\title{
Total Integrative Evolutionary Communication: Towards a Cybersemiotic Discourse Pragmatics
}

\author{
Ole Nedergaard Thomsen and Søren Brier
}

\begin{abstract}
In this paper we outline a cybersemiotic foundation for the trend of pragmatics-based functional linguistics, Functional Discourse Grammar. Cybersemiotics is a substantial inter- and transdisciplinary semiotic theory which integrates, on the one hand, second-order cybernetics and autopoiesis theory and, on the other, Peircean biosemiotics. According to Cybersemiotics, language is primarily a creative process of total integrative evolutionary communication. It comprises three evolutionary stages: (1) biological reflexive languaging (the reflexive foundation of social coordination), (2) instinctual-motivational-emotional sign plays (a level which is shared with other animals and is the domain of ethology), and (3) premeditated, intentional symbol-based language games (specifically human unitary thinking-speaking-gesturing, the domain of pragmatics-based functional linguistics). In this inclusive hierarchy language games subsume the other stages, and thus human evolutionary communication is primarily a symbolic-conventional practice. It is intertwined with the practice of living, that is, with different life forms, including other forms of semiotic behavior. Together they form a coherent biological and socio-cultural practice. The basic "molecule" of the cybersemiotic model of human communication is a dyad between two linguistic cyborgs, alias natural language users. Single human communicators are thus "atoms". They are hybrids between nature and nurture, manipulating all sorts of artificiality (e.g. pen and ink writing, digital-electronic texting, mobile telephonic amplification). A conventional practice, language occurs in three phases: as discourse process, product, and pattern. As discourse pattern it is deontological-directive (rather than epistemic-declarative) and functions as a finalistic guideline for the communicative processes of single individuals. Thus, rather than being the speech community's invariant langue, a discourse pattern is a single individual's communicative competence. Accordingly, shared communicational norms and conventions of the speech community are emergent and not determinant.
\end{abstract}

Keywords: Cybersemiotics, Functional Discourse Grammar; total evolutionary communication; linguistic cyborg, Natural Language User; languaging, sign plays, language games; language as process, pattern, and product; Peircean Pragmaticism; Coşeriu's Integral Linguistics

\section{Introduction: Towards a cybersemiotic foundation of Functional Discourse Grammar}

Our specific focus is that of improving the explanatory adequacy of Functional Discourse Grammar (e.g., Hengeveld \& MacKenzie, 2008; Nedergaard Thomsen, 2008). ${ }^{1}$ We want to do this by supplying it with a comprehensive inter- and transdisciplinary cybersemiotic foundation (see Brier, 2008), integrating it with cybersemiotic communication and cognition theory. It will thereby be improved with regard to its socio-pragmatic and individual and social psychological explanatory adequacy (cf. cyber[netics]), as well as to what we shall term semiotic adequacy. More precisely, it will have to be adequate in four explanatory spheres of human reality (cf. the Cybersemiotic Star, Appendix A): (1) physical-chemical-informational, (2) biologicallife, (3) phenomenological-hermeneutical-individual-psychological, and (4) socio-

\footnotetext{
${ }^{1}$ Functional Discourse Grammar (Hengeveld \& Mackenzie, 2008) following Functional Grammar (Dik, 1997; Hengeveld \& Pérez Quintero, 2001), in addition to observational adequacy claims typological and language-specific descriptive adequacy, and psychological and pragmatic explanatory adequacy.
} 
cultural, both idiosynchronically and in an evolutionary and developmental perspective. ${ }^{2}$ The epistemological problem is that what is to be explained, human semiotic communication and cognition, is exactly the same reality as that used in the explanation: human semiotic communication and cognition (i.e. the epistemological core in the middle of the star). Cybersemiotics is thus second-order cybernetics.

However, the aim is reciprocal, since we also want to improve and revise Cybersemiotics by expanding it with a compatible grammatical-pragmatic linguistic component. We have chosen the above-mentioned model Functional Discourse Grammar for this, rather than for example Systemic-Functional Linguistics (e.g., Halliday \& Matthiessen, 2000, 2004), or any other cognate brand of current linguistic theories, like for example Cognitive Grammar (e.g., Langacker, 1987, 1991, 2001; see Armstrong, Stokoe, \& Willcox, 1995). The reason is that Functional Discourse Grammar is a simple, realistic (organon) model of language as an instrument of communication, which, as emphasized above, indeed aspires to both socio-pragmatic and psychological explanatory adequacy. Systemic-functional Linguistics and Cognitive Grammar strive for a narrower explanatory adequacy: Systemic-Functional Linguistics is more biased towards sociopragmatic adequacy, Cognitive Grammar more towards psychological adequacy. In terms of semiotics/semiology, Functional Discourse Grammar is compatible with Peircean triadic semiotics, whereas Cognitive Grammar and Systemic-Functional Linguistics (Fawcett, 1983) are more in line with Saussurean dyadic semiology (Nedergaard Thomsen, 2014). The extra term in the triadic sign model, the semiotic Object, is present in Functional Discourse Grammar's underlying structures in terms of referential variables, and in the contextualizing Contextual Component (Hengeveld \& Mackenzie, 2014).

Functional Discourse Grammar is based on Levelt's (1989) information processing theory of language production from intention to articulation, with the explicit proviso not to be a model of the Natural Language User, but only of language or grammar per se. This is indeed contradictory, bearing in mind that the model is intended to be pragmatically and psychologically adequate and is in explicit opposition to the aspiration of its predecessor Simon Dik's [1997] Functional Grammar, whose final aim was to be a model of a human being in terms of linguistic, social, and cognitive capacities - a "wider theory of human interaction" and a "wider theory of the human mind" (Hengeveld \& Mackenzie, 2014). The theory that we want to propose here takes seriously the claim that what one should aim at is exactly a model of the actual linguistic communicators, their embodied, situated communicative competences, their communicative interactions, and their communicative products.

Cybersemiotics revises Luhmann's (1995) transpersonal, socio-communicative, autopoiesis-based systemic sociology by recognizing human personal agency as a building block (Brier, 2006, 2007). This means that an individual communicator is a social "atom" and with another communicator forms a communicating dyad as a social "molecule". Of course, agency is especially relevant in the context of the upper level of evolutionary communication, of premeditated-intentional language games (Mead, 1934; Wittgenstein, 1953), since here free will, consciousness, expressive creativity, and accountability (commitment) are crucial. The lower levels of evolutionary

\footnotetext{
${ }^{2}$ Note that technology overlaps all four arms of the cybersemiotic star. All aspects are (part of) nature, thus absolute naturalism. Depending on one's worldview, everything may also be informational and/or semiotic.
} 
communication, languaging and sign playing, are not premeditated (Brier, 1995, 2003). However, they can be re-enacted in conscious play-acting, or be feigned. In this way, the deterministic-non-volitional automatisms of languaging and sign plays interact with basically indeterministic-volitional, finalistic language games. The responsibility lies with the single linguistic communicators operating in tandem. ${ }^{3}$

The human communicator is what in Cybersemiotics (Brier, 2008) is termed a linguistic cyborg, a hybrid between culture-artificiality (cf. cyb, from "cybernetics"; cf. language games), on the one hand, and nature (cf. org from "organism"; cf. languaging and sign plays), on the other. We conceive of this as "second order" nature, not as a dichotomic dualism. Therefore, we speak of "total integrative evolutionary communication", and extend the use of the term "languaging" to also include "sign play" and "language game".

The concept of human agency is thus to be considered in the wider context of the linguistic cyborg. Humans are viewed as animal "sign-systems" immersed in language and the culture that peruses it. The human self and its intersubjective self-consciousness are partly created hereby, through the capacity to conceptually represent oneself. Human discourses, e.g. conversations, are the purview of human beings in their totality (i.e., bodily persons with embodied minds and bodily extensions). That is why, in Cybersemiotics, we speak of communicating bodies and persons as opposed to "talking heads" (Nedergaard Thomsen, 2010), and stress the fact that human communication is a disposition and skill of the total embodied human person. Thus, we diverge from Luhmann's attribution of agency to only communication itself ("only communication communicates") and from Latour's attribution of agency to texts and other actants, stressing that non-agents like communication and its textual outcomes are not really accountable. Solely human beings as social persons can be accountable-anything else would be a category mistake.

Taking whole human bodies and persons as communicative agents, or communicators, makes it possible to understand languaging (in the broad sense of total communication) as body languaging (in the strict, literal sense) and the whole body as the articulator of its external semiotic displays. But we will not end here: We extend the picture to comprise all sorts of artifacts functioning as articulators in other media-these are extensions of the human body in human total communication. For example, consider a fan used by a woman in flirting, a pencil used in writing, a keyboard in typing, a pointer used by a teacher when pointing at a map. Conspicuous clothing and piercings are also extensions of the human body in total communication functioning as semiotic displays.

It will by now be obvious that human beings are, in fact, halfway artificial-cultural, halfway natural. This extension of semiotic articulation in communication is comparable to the amplification of our minds in cognition, as for example when we rely on a calculator in doing arithmetic. Evidently, an integrated, distributed cognition and communication theory is possible, as proposed in Distributed Language Theory (Cowley, 2011; Thibault, 2011; Cowley et al., 2014). However, we are rather skeptical about the whole-sale integration of the theories of the extended mind (e.g. Clark, 1998) and

\footnotetext{
${ }^{3}$ Note that in the non-human animate world instances of semiotic "deceit" also occur, for instance when a parent bird plays wounded to draw a predator's attention away from the bird's offspring. However, they are spontaneous, stimulus-triggered sign plays, not premeditated language games.
} 
distributed cognition (e.g. Hutchins, 2000), simply because it implies the obvious neglect of personal accountability, and thereby of the principle of habeas corpus, as well as of the individual basis of sensori-motor speech processing and of the intentions and emotions verbalized and expressed in speech production.

Our cybersemiotic understanding of human communication as total and integral is aptly illustrated by the following painting showing a scene of flirtatious communication (see Picture 1). Of course, we can only guess at the specific verbal language games being played by the standing man and his interlocutor, the nearest sitting young lady, but the visual, postural, and facial displays are very telling. In fact, they are the primary indication that we are confronted with an instance of flirting. We might even say that the sign play and languaging levels are primary in this case. Furthermore, the whole behavioral scene is integral, intertwining the communicative practice with the biological (mating) and cultural (courtship) practice of living.

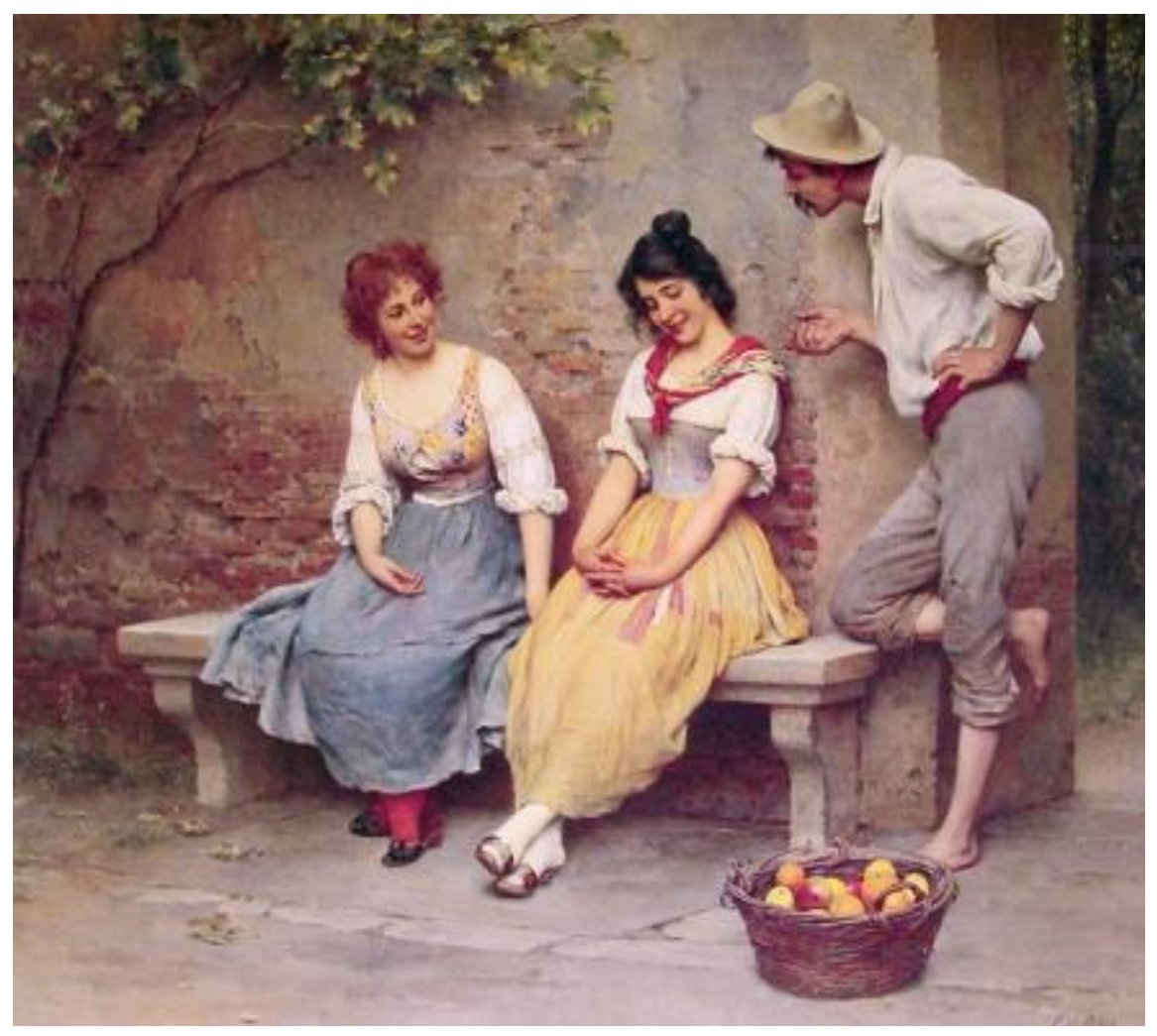

Picture 1. Eugene de Blaas: The Flirtation, 1904

In principle, language games, which are spatio-temporal phenomena, are undocumentable in a (static) painting. Only in (dynamic) moving pictures with sound can we ascertain them fully. A language game is in itself an integration: The verbalpropositional level, which cannot be seen in the picture (it could be read in a cartoon), is 
co-expressed with a non-verbal, gesticulative imagistic-indexical level (McNeill, 2005; Kendon, 2004), which is displayed by the man's finger gesture in the picture.

\section{The natural language user alias linguistic cyborg}

Luhmann's social systems theory does not recognize the role of the single individual Natural Language User. Brier (2006) speaks of the missing bodily situated subject. This neglect of the linguistic subject - both in Functional Discourse Grammar's focus on the grammatical pattern and in Standard Social Systems Theory's exclusive focus on the communicative process - is theoretically unsatisfactory. First, the observation and registration of actual linguistic performance on the level of operative human voluntary agency, e.g. authored linguistic usage, ${ }^{4}$ is the empirical prerequisite for being able to unearth (describe and explain) the linguistic structures (patterns, habits) that function as targets for performance. Furthermore, these structures are functionally adapted to, or grown out of, performance (Hopper, 1988; Dik, 1997; Hawkins, 2004; Langacker, 2000).

A human interactional-communicative subject has at his disposal a set of competences: At the top level, a communicative competence (Hymes 1972; Kurcz 2004), i.e. a competence for how to premeditatedly, self-consciously play intersubjective symbolic-conventional language games in his language(s). At the intermediate level, his unconscious repertoire of instinctual-motivational-emotional sign plays and the bedrock of the innate capacity for reflexive languaging (behavioral coordination) at the bottom level.

A language game (conversation, discourse), to be sure, is intersubjective. It is fundamentally dialogical and reciprocal, built up by constitutive turns performed by the individual communicators according to their collective, we-intentionality (Searle, 1990) for enacting collective actions, co-actions. Simultaneously, the single communicating cosubjects act according to individual, I-intentionality for performing individual acts (personal choices). This way, the public-social, interpersonal level is individually, personally anchored.

The biological basis of the communicative competence is an inherited, universal communication faculty. According to Chomskyan biolinguistics (see Chomsky, 2007; Hauser, Chomsky \& Fitch, 2002; Fitch, Hauser \& Chomsky, 2005), this faculty comprises peripheral performance systems and a central computational lexicogrammatical competence system. As regards language evolution, we side with Jackendoff $(2002,2011)$ in viewing this intra-personal language faculty as integrated with other systems of the mind-brain (see Figure 1), rather than being strictly encapsulated.

\footnotetext{
${ }^{4}$ This is the purview of the linguistic disciplines of articulatory and auditory phonetics, psycholinguistics, neuro-linguistics, socio-linguistics, stylistics, and rhetoric/pragmatics.
} 
Nedergaard Thomsen and Brier

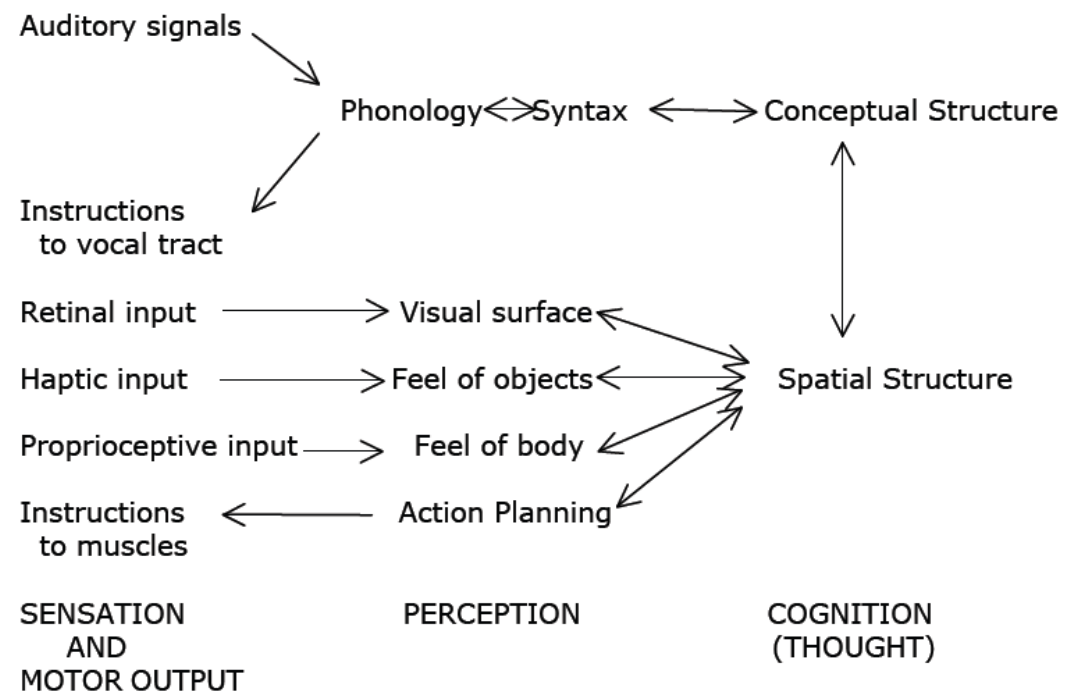

Figure 1. Jackendoff's Parallel Architecture Model. Language communication (first line) is in this model seen in relation to the other input capacities of the mind/brain (Jackendoff, 2011, Fig. 7)

We mentioned above that the basic building block of the speech community and the functioning communicative system is the individual socio-cultural person. Our model is accordingly (inter-)individualistic, bottom-up. Luhmann's systemic sociology, on the other hand, is collectivistic, top-down: The communicating "subject" is a derivative notion in his transpersonal, autopoietic model. ${ }^{5}$ Against this, we believe that the social system is an individual-based, collective accomplishment, a sympoietic system (Dempster, 1998, 2000) contracted by way of communications of liable autonomous individuals (see Searle, 2010).

The communicator is a speaker-listener. Both as sender and as receiver the communicator is accountable (cf. you can intentionally misunderstand). Communication is the interdependence and integration of message production and message reception, as shown in Figure 2 (cf. Strohner, 2001):

\footnotetext{
${ }^{5}$ In Luhmann's model there are three interpenetrating autopoietic systems, viz., the personal psyche, the biological body (organism), and society (understood as a generalized communicative system). The personal subject, which is not a Luhmannian concept, can then be construed as emerging out of the intersection of these three autopoietic systems.
} 


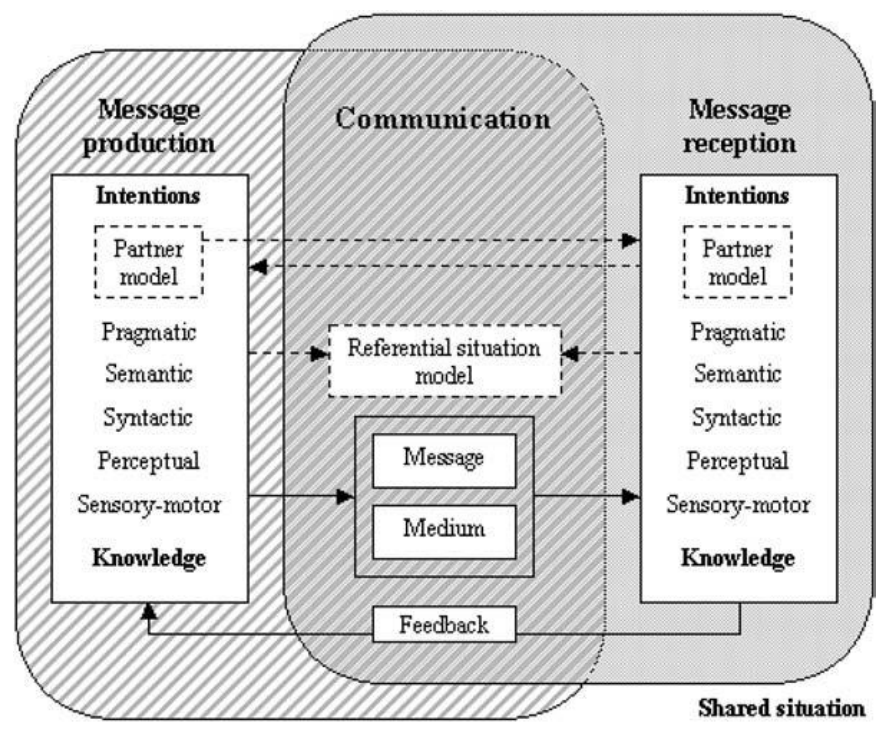

Figure 2. Communication as the Integration of Message Production and Message Reception

We proposed above that man is a natural-nurtural linguistic cyborg, that is, a sensori-motor biological organism as well as a rational-intentional, "speech-acting" cultural person. In conformity with this, each individual lives "in" an integrated individual sensori-motor Umwelt (von Uexküll, 1909; Brier, 2008) as well as an individual, cultural-linguistic signification sphere (Brier, 2008). Only derivatively, the totality of the speech community, as a population of speakers, lives in an aggregate cultural-linguistic signification sphere (Brier, 2008). It is heterogeneous-variational, not monolithic, since it represents the different knowledge systems, conventions, and practices of the various fractions (e.g. social strata) of the community. Outside the signification spheres, there is a dynamically objective Umgebung, an environment surrounding the communicators and their communities. Correlated with the Umwelt, there is an Innenwelt (von Uexküll, 1909), or referential situation model (see Figure 2).

\section{The entire person as communicator: Talking heads and communicating bodies}

The theory of Functional Grammar (the precursor of Functional Discourse Grammar) by the late functional linguist Simon C. Dik (Dik, 1997) fares much better than Functional Discourse Grammar, in that its ultimate theoretical object of observation, description, and explanation is the so-called Natural Language User, his competences, communications, and texts. A Natural Language User is an integration of linguistic capacities with logical, epistemic, perceptual, and social capacities (Dik, 1997a, 1ff; Dik, 1997b, 409ff). Even though we believe Dik's original model to be ahead of much of contemporary linguistics - even its successor, Functional Discourse Grammar - we also believe it still to be insufficient on many accounts. The primary one is its neglect of a total perspective on communication including the pre-verbal reflexive and instinctualmotivational levels of communication. Functional Discourse Grammar should therefore 
include ethological, biosemiotic adequacy for the evolutionarily pre-verbal modes of communication, which are integrated with the verbal language games. Additionally, paralinguistic adequacy must be recognized for the para-verbal modes of communication: Face-to-face verbal communication on the level of language games is invariably intertwined with gesticulation (Kendon, 2004), or manual imagistic-indexical gestures (McNeill, 1992). ${ }^{6}$ Our point of view is thus succinctly formulated by McNeill (1992):

\begin{abstract}
A conception of language and gesture as a single integrated system is sharply different from the notion of a "body language" - a communicational process utilizing signals made up of body movements, which are regarded ... as separate from and beyond normal language ... Rather than causing us to slice a person analytically into semi-isolated modules, taking gestures into account encourages us to see something like the entire person as a theoretical entity-his thinking, speaking, willing, feeling, and acting, as a unit. (McNeill, 1992, p. 11; McNeill's bold, our italics)
\end{abstract}

We agree with McNeill in understanding language and gesture as a single integrated system (with a genetic thought-gesture-speech link; McNeill, 2005, 2006) of an entire non-modular person. However, we believe that McNeill's (1992) single integrated system is only part of the total communicator, namely, the verbal-gestural top level. What are evidently lacking are the human-ethological levels, alluded to above, namely, the proto-semiotic reflexive level of languaging and the pre-linguistic level of motivational-emotional sign plays. The concept of a total communicator thus requires an integrated, multimodal semiotics. ${ }^{7}$

Integrating the frameworks of Cybersemiotics and Functional Discourse Grammar, we can work towards a Cybersemiotic Discourse Pragmatics, with stress on pragmatics (function) rather than grammar (form). We want to replace Grammar with Pragmatics because, as maintained above, the object of investigation should be the integral communicative competence rather than a narrow verbal-grammatical competence, and because the pragmatic domains of discourse processing and interactivities and their discursive-textual products are complementary constitutive parts of the total picture. In our view, a viable pragmatics must be one that studies all sorts of communicative habits, including the use of strictly grammatical forms and structures, both in their formal and their functional aspects. Pragmatics thus defined could be said to integrate grammatica, rhetorica (context and situation), and dialectica (conversational logic). We retain the term Discourse for our model, since it emphasizes that the crucial, defining rank is discourse and communicative interaction. By targeting function instead of form, by focusing on conversation and its constitutive discourse acts rather than on word and sentence (the formal lexico-grammatical levels of morphosyntax plus phonology and semantics), we focus on a wider theory of human communication and mind and thereby

\footnotetext{
${ }^{6}$ There is a significant difference between the species-specific, and therefore universal, languaging and sign play gestures (signals) and the language-specific iconic gesticulation, where e.g. iconic imaging of a motion event is dependent on the specific linguistic type of the language used in the language game, e.g., profiling either the direction or the manner of the motion depicted.

${ }^{7}$ As mentioned above, we term the total communicator a linguistic cyborg, owing to the fact that verbal language is the ultimate, defining and subsuming level, and that man, even though he is a naturally born organism (... and that's not even true, alas! - giving birth is also a cultural institution), he is a cultural, cybernetic-artificial creature.
} 
Public Journal of Semiotics 6 (1)

on psychological and socio-pragmatic explanatory adequacy, which, in opposition to Functional Discourse Grammar (Hengeveld \& Pérez Quintero, 2001), we do not view as extralinguistic. Language is function as well as form, "etics" as well as "emics".

Basing ourselves on the scientific object of the linguistic cyborg, or total communicator, our pragmaticist biolinguistics should take its starting point in the creative communicative competences (dynamis) of historically identifiable language users (Bloch, 1948). Furthermore, we do not wish to limit ourselves to idiographic psychology and sociology of language, but aspire to be nomothetic (Jakobson, 1971).

A communicative competence is not an individual's private language (such a thing does not exist), but an individual's public dialect, convention. My language is taken to be our language. We have to make this presupposition if we want to make ourselves understood. Chomsky operates with a speaker-listener in this connection, underlining the ability to perform any active, direct part in a conversation. But we also want to include other more passive roles outside as well, for instance that of bystander (Rijkhoff, 1995; see the second young woman in Picture 1). We always function as speaker-listeners in either mode of communication (in speaking, monitoring our speech, adapting it to the addressee/audience; in listening, placing ourselves in the position of the addresser). Communication is a manifestation of a personally functioning collective weintentionality (Searle, 1990, 2010). What this means is that $I$ intend my discourse act as part of our conversation, in which you are also involved as an $I$, and thereby $I$ as a you (compare this with the single instrumentalists in a symphony orchestra co-performing a symphony).

\section{Integrating Coşeriu's Integral Linguistics: Actual, virtual, possible process}

Owing to the fact that the object of investigation should be basically several single individual linguistic cyborgs and their actual embodied, situated communications, but also, derivatively, nomothetic generalizations over and explanations of these unique idiographic factors, ${ }^{8}$ our model must incorporate a linguistic theory that, in addition to the strictly individual, operative level, also focuses on higher levels of generality and abstraction. Such a theory is Eugenio Coşeriu's Integral Linguistics (e.g., Coşeriu, 1985, 1992). Metatheoretically it distinguishes a rational level of explanation, a general level of description (typology and classification), and a specific level of observation (data and registration). Empirically, in terms of the object of investigation, a universal level of the phenomenon of language (langage), a historical-general level of a specific language as a general-purpose code (langue), and an individual-particular level of a situated, stylistic code (parole) are distinguished. This distinction concerns generality/abstraction, or applicability domain. On the dimension of reality, the latter tripartition is tripartitioned into three phases. Given that language is a processual phenomenon (energeia "creative activity"), it occurs in an actual, existential phase, a virtual phase (dynamis "pattern"), and a product phase (ergon). These factors are context-sensitive and correlated with a context (Coşeriu 1955-56).

\footnotetext{
${ }^{8}$ We hesitate to say probabilistic (stochastic, casuistic) because this is only a statistical way of describing phenomena which are the result of a constrained, conventionalized exercise of free expressive will and creativity as well as linguistic productivity.
} 
We base our model on the (inter-)individual-particular level since communication is performed by dyads of single individuals in particular individual, concrete situations. This pragmatic-rhetorical focus on the concrete individual communicators in the concrete individual communication situation implies a focus on the here-and-now interactivity phase of communication. This phase, according to Coşeriu, following Aristotle and von Humboldt, is the telic actual creative energeia, or entelechy. Functioning as guidelines for the interactivity and processes of communication are the constraining, constituting as well as regulating communicative norms or patterns of behavior (methods of communicating), for short the communicative competences of the speakers. This is Aristotelian dynamis. What results from, or emerges out of, the communicative interactivity is, on the object level of communication, the ensuing text. This aspect of historical accomplishment is Aristotelian ergon, represented, for example, by an ordinary conversation as a fait accompli, a literary work of art, or a recorded political discussion. They may be (partially) retained in memory, and may be reproduced in discourse (as wiederholte Rede, e.g., proverbs, citations). On a meta-communicative level, the competence itself is continually (re-)created and updated by and in communicating (Nedergaard Thomsen, 2006, 2014). In this way, the convention grows out of the process as a historical result (Peirce, 1923[1998]). Thus, a given communicative competence is simultaneously a synchronic-functional practice of speaking and a diachronic (acquired and learned, respectively transmitted) tradition of speaking, on the foundation of the constitutive panchronic language faculty (Nedergaard Thomsen, 2014). So, a given individual speaker's dialect is a chronolect, a historical outcome pointing to a connection between synchrony and diachrony: generational acquisition, transmission, and change.

What we have described up until now is solely the operative idiosynchronic stylistic-expressive level of the here-and-now of embodied, situated language use. This is a level that in most grammatical theories is by-passed since it involves all sorts of socioand psycholinguistic variation. Functional Discourse Grammar explicitly disclaims this "etic" level (Hengeveld \& Mackenzie, 2014). Instead, it is focused on the next level of generality and abstraction, the "emic" historical-general, regulative idiomatic level, corresponding to the Saussurean langue. This is the level of the linguistic system, which in Coşeriu's conception is an individual's procedural linguistic competence.

The individual language user's synchronously operative functional competence here-and-now (his linguistic practice) is part of the succession of the phases of his competence. They develop from the innate faculty of communication at birth, over (epigenetic) maturation, acquisition, and learning throughout the first years of life to a mature competence after puberty, and perhaps turn into a decaying competence at the end of life. Evidently, a communicative competence is an ontogenetic process phenomenon. This variational dimension is also left out in Functional Discourse Grammar but will be prominent in Cybersemiotic Discourse Pragmatics.

The individual speaker-listeners contract aggregate we-groups: communities of practice (on the interindividual-particular level) and speech communities (on the historical-general level). The sum total of the individuals' synchronic practices of speaking, within a given specific speech community, is an aggregate (variational) historical language, what Coşeriu terms an idiom or speech community diasystem. This is another variational dimension that is neglected in Functional Discourse Grammar but which is utterly relevant within the domain of explanation of Cybersemiotic Discourse 
Pragmatics. This is so because it concerns the glossogenetic tradition of speaking, in the diachronic dimension the development of language traditions, which is the topic of comparative historical linguistics and reconstruction.

The last dimension we want to stress, crucial in an evolutionary model of communication, is the panchronic dimension of the phylogenetic-universal language faculty. It concerns the innate language-universal and cultural-neutral communicative competence, shared by all members of the human species and dealt with by a universal discourse pragmatics. In terms of the processing, energeia aspect, this would correspond to the type of communicating, for example the pragmatic universal discourse act of asking questions, and in general, the universal taxonomy of discourse acts and types of discourse. In the evolutionary perspective, we deal with the threshold and continuity between (non-symbolic) reflexive languaging and sign plays and symbolic, deontological-conventional language games and the evolution of the "symbolic species" (cf. Deacon, 2012). To summarize on the historical dimension of communication: Ontogenesis concerns the ontogenetic development of the communicative competence of the individual language user (inheritance, maturation, and lifelong learning); glottogenesis concerns the gradual historical change of the idiom of the speech community over time (as generated by the individual idiomatic competences); phylogenesis targets the biosemiotic and biolinguistic evolution of the human capacity for communication, from reflex over instinct to rational language game.

Linguistic communication will be conceived of as in the following cross-tabulation (see Table 1; Coşeriu 1985; cf. Zlatev 2011 for a related but different interpretation), where the horizontal dimension constitutes the phases of communication and the vertical dimension constitutes the levels of abstraction as applied to the phases. This yields nine cells with each one representing an important, complementary facet of language and communication. The middle level of abstraction, the historical-general level, is further trifurcated, as hinted at below (Coşeriu 1980). Note that the pattern phase is trifurcated, in that we recognize language as a diachronic tradition, a synchronic practice, and the panchronic-universal linguistic faculty.

Table 1. Cross-tabulation of Communication. ${ }^{9}$

Vertical: level of abstraction; horizontal: phase of energeia

\begin{tabular}{|l|l|l|l|}
\hline $\begin{array}{c}\text { Verbal communication } \\
\text { linguistic } \text { energeia }\end{array}$ & \multicolumn{1}{|c|}{$\begin{array}{c}\text { entelechy (process) } \\
\text { speaking phase }\end{array}$} & $\begin{array}{c}\text { dynamis (pattern) } \\
\text { language phase }\end{array}$ & $\begin{array}{c}\text { ergon (product) } \\
\text { speech/text phase }\end{array}$ \\
\hline $\begin{array}{l}\text { individual-particular } \\
\text { level of abstraction }\end{array}$ & $\begin{array}{l}\text { speaking as a situated } \\
\text { process/communicating }\end{array}$ & $\begin{array}{l}\text { stylistic-situational } \\
\text { expressive competence }\end{array}$ & $\begin{array}{l}\text { unique text in textual and } \\
\text { situational contexts }\end{array}$ \\
\hline $\begin{array}{l}\text { historical-general level } \\
\text { of abstraction }\end{array}$ & $\begin{array}{l}\text { speaking a specific } \\
\text { language } \text { (idiom) }\end{array}$ & $\begin{array}{l}\text { historical-general } \\
\text { idiomatic } \text { competence }\end{array}$ & $\begin{array}{l}\text { the corpus of texts of a } \\
\text { given speech tradition }\end{array}$ \\
\hline $\begin{array}{l}\text { universal level of } \\
\text { abstraction }\end{array}$ & $\begin{array}{l}\text { speaking/dialoguing } \\
\text { (universally) }\end{array}$ & $\begin{array}{l}\text { universal-pragmatic } \\
\text { elocutional competence }\end{array}$ & $\begin{array}{l}\text { text as a universal type, } \\
\text { every possible discourse }\end{array}$ \\
\hline
\end{tabular}

The individual's communicative competence, by being quite specific and adapted to the moment of utterance, is an expressive, rhetorical competence. The stylistics and situation-specific norms of usage are operative and give rise to the evaluation of the

\footnotetext{
${ }^{9}$ We have placed the individual-particular level in the uppermost row and the universal level in the bottom row of the table to mirror the fact that the universal level is the foundation of the other levels.
} 
situational acceptability of the ensuing speech. It is a discourse mechanism. Besides being expressive, the individual's competence is part of a more comprehensive linguistic convention - it is a general-purpose idiomatic competence. This means that in addition to the synchronic core of his idiomatic competence (Coşeriu's functional system) and the evaluation of systemic correctness, e.g. grammaticality, the communicator's competence also has a diachronic layer (Coşeriu's functional norm) with evaluation in terms of normative idiomaticity. Lastly, the individual's idiomatic competence, on its most general level, is or belongs to a functional type (Bauplan), a specific selection from the universal possibilities, forming the coherence of the norm and system of his idiomatic competence (Coşeriu, 1980). The communication going on thus manifests communicating in general as a universal human behavioral process (e.g., asking and answering questions) constrained by the universal functional discourse pragmatics contained in the communicator's elocutional competence, but it also occurs in accordance with a specific holistic linguistic type. This typological-linguistic factor is crucial in Functional Discourse Grammar (Hengeveld \& Mackenzie, 2008).

A further, circumscribing level, according to Coşeriu, is the physical and biological (and psycho-somatic) levels. ${ }^{10}$ For one thing, language and speech occurs in physical reality, and its textual manifestation is itself part of the physics (e.g. acoustics). The peripheral, phonetic performance system is adapted to acoustic reality, and the phonological system is adapted to the physiological processing of acoustics (for instance properties of phoneme systems as determined by the perceivability of phonetic contrasts). For another, competence is "wetwired" neurally. In this connection it is important to look at the given instance of communication in terms of biological, psychiatric, and psychological normality: Is the speech, for example, stuttering, aphasic, or schizophrenic? This kind of clinical linguistic and phonetic disordered variation is substantial evidence that will give a window onto the clinically normal. This is also left out of view in Functional Discourse Grammar, but was crucial, surely, for Roman Jakobson's structural functionalism.

\section{The total communicator: multimodality}

To be publicly and physically perceivable, a text must be manifested in a physical channel or medium (Jakobson, 1960). In line with our multimodal model of total communication, there are several simultaneous channels, such that each instance of communication occurs simultaneously in specific communicational modalities, verbal as well as nonverbal. The different expressional modalities are coupled with different codes, that is, inventories of signs manifested in these modalities. This means that, given "the medium is the message" (punning on McLuhan's 1964 catch phrase, where "message", however, meant unorthodoxically the perlocutionary, unforeseen, effect of the medium), the specific medium determines a specific kind of content, tinted by it. Thus, on the level of language games, we have the vocal or signed modality and the corresponding verbal codes and the manual-gestural modality and its corresponding nonverbal gestural "codes". The multimodal structures of multimodal texts are accordingly due to a multimodal communicative competence. We term this competence inter-

\footnotetext{
${ }^{10}$ These are matters of physical and (psycho-)biological adequacy, in terms of the Cybersemiotic Star (cf. Appendix A)
} 
pragmatics (cf. "inter-grammar" in Arndt \& Janney, 1987). ${ }^{11}$ Multimodality is not part of Functional Discourse Grammar, with its traditional verbal focus. However, to be semiotically adequate, this kind of semiotic "complification" has to be dealt with.

Verbal-symbolic language games incorporate or host complementary paralinguistic levels of iconic manual gesticulation, indexical pointing and nodding, and postverbal symbolic-emblematic signing (e.g., the $\mathrm{V}$ emblem for victory, with a $\langle\mathrm{v}\rangle$, is evidently dependent on post-vocal writing, but also headshaking, arbitrarily signaling polarity either by nodding vertically or horizontally, waiving, begging, greeting, in culturally different ways; cf. Kendon, 2004). We additionally subscribe to McNeill's hypothesis of a genetic thought-gesture-speech link on the level of language games. Generalizing Coşeriu's three phases described in Section 4, total evolutionary communication is an integral communicative capacity or pattern, a semiotic process, and a textual product.

The sign plays and language games constitute that part of total communication that is controlled or monitored by the linguistic cyborg's psyche, intentionally-volitionally and spontaneously-emotionally-motivationally, respectively. It should not go unnoticed, however, that sign plays may be faked (Buck et al., 2002), as evidenced by pseudospontaneous non-verbal behavior, where a sender intentionally tries to manipulate a receiver by feigning spontaneous emotional-motivational signs (see Figure 3 below, from Buck \& VanLear, 2002, p. 527). This is well-known from theatrical acting (cf. ancient Greek rhetorical hypocrisis).

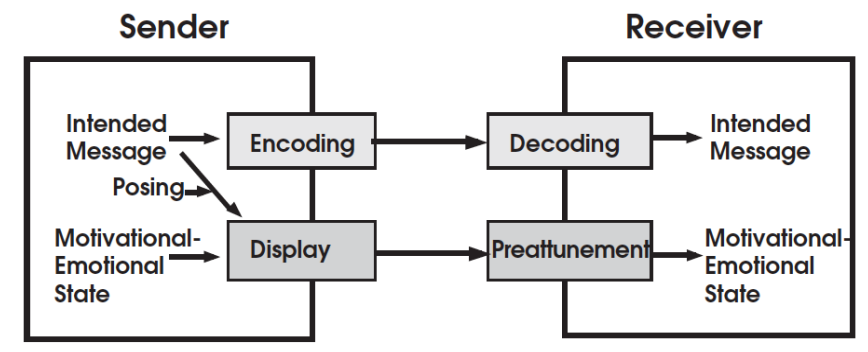

Figure 3. Symbolic Communication (“coding”, comprising verbal language games plus i.a. iconic-analogic gestures) and Spontaneous Communication ("displaying”, indexical sign plays), Plus Pseudo-spontaneous (i.e. intentional) Sign Plays ("posing”, i.e. faking a given motivational-emotional state)

According to substantial evidence from brain damage, language gamescomprising both verbal propositional-symbolic and nonverbal non-propositional-analog threads - seem to correlate with activity in the left hemisphere of the brain, whereas motivational-emotional sign plays tend to go with neural activity in the right hemisphere (Buck \& VanLear, 2002). Thus, damage of the left hemisphere leads to deficits on the level of language games: propositional-symbolic verbal behavior as well as nonpropositional-analog nonverbal communication, and premeditated, pseudo-spontaneous posing. Right hemisphere damage may cause deficits in emotional-motivational sign plays. To reiterate, these two divergent but complementary types of communication, the socio-psychological language games and the bio-psychological sign plays, are organized

\footnotetext{
${ }^{11}$ In a similar vein we venture a "the code is the message", implying that the specific type of language that you speak co-determines the way you think, as proposed in Slobin's (1987) "thinking-for-speaking", the Humboldtian Linguistic Relativity, inherited by Sapir and Whorf-and others as well.
} 
through evolutionary processes on species level. The sign plays represent an earlier stage (i.e., old mammalian brain), the language games the more recent stage (i.e., new mammalian brain). Within the latter, symbolic stage, the iconic and indexical gesticulation sublevels are evolutionarily ordered before the symbolic-verbal host level (a preverbal infant may use pointing), whereas language-slotted (see Langacker 1987) and emblematic symbolic signing are postverbal.

The lowest level of total evolutionary communication, that is, the level of reflexive languaging, reflexive copying of one person by another, or mimicry, correlated with a cortical mirror neuron system (Rizzolatti and Sinigaglia, 2010), facilitates empathy, the prerequisite for the psychological contact in communication, which is the opposite number of the physical contact in the medium (Jakobson, 1960).

The resulting picture of a human communicator is that of a linguistic cyborg as a symbolic general purpose processing system and an indexical special purpose processing system biologically preprogrammed for performing sign plays, as well as an iconic foundational processing system. The recognition of this macro-system is part of biological adequacy.

\title{
6. The cybersemiotic revision of the Functional Discourse Grammar conception of grammar
}

Having placed Functional Discourse Grammar within the wider picture of human total integrative evolutionary communication, we are now in a position to go into more details with its revision as a Cybersemiotic Discourse Pragmatics.

\subsection{FDG's conception of a grammatical component}

To get an idea of the conceptual basis of Functional Discourse Grammar (for short, FDG), let us start out with two quotes from Hengeveld \& Mackenzie $(2008,2010)$ :

\begin{abstract}
a. FDG starts with the speaker's intention and then works down to articulation. This is motivated by the assumption that a model of grammar will be more effective the more its organization resembles language processing in the individual. Psycholinguistic studies (e.g. Levelt 1989) clearly show that language production is a top-down process, which starts with intentions and ends with articulation of the actual linguistic expression. The implementation of FDG reflects this process and is accordingly organized in a top-down fashion. This does not mean that FDG is a model of the speaker: FDG is a theory about grammar, but one that tries to reflect psycholinguistic evidence in its basic architecture. (Hengeveld \& Mackenzie, 2008, p. 1; our emphasis)

b. Functional Discourse Grammar (FDG) is a typologically based structural-functional theory of language. It has a top-down organization to achieve psychological adequacy, and takes the Discourse Act as its basic unit of analysis to achieve pragmatic adequacy. Although itself strictly a model of grammar, FDG is designed to interact with Conceptual, Contextual, and Output Components, so as to enhance its compatibility with a wider theory of verbal interaction. (Hengeveld \& Mackenzie, 2010; our emphasis; see Figure 4 below from Hengeveld \& Mackenzie 2008, p. 6))
\end{abstract}

The above quotations unequivocally show that FDG, although without admitting it directly, endorses a clear-cut distinction between competence ("FDG is a theory about grammar") and performance ("This does not mean that FDG is a model of the speaker, the purview of a wider theory of verbal interaction"), and directly purports to be a 
Public Journal of Semiotics 6 (1)

"theory of grammar" (competence) rather than of the individual speaker, his communicative capacities, and his discourse processing (performance). From the above quotations, it is unclear whether "grammar" is meant to be strictly a Chomskyan autonomous mental module, i.e. a generative-computational system of an ideal individual speaker-listener. In this case it would be a declarative grammar ("theory") theoretically abstracted from actual speaker-listeners' empirical procedural grammars. Alternatively, it could be meant as an extra- or trans-individual Saussurean monolithic langue of the speech community. However, Functional Discourse Grammar, by leaning on Levelt's production model and given its Dikian inheritance, would be more in line with Chomskyan internalism or mentalism.

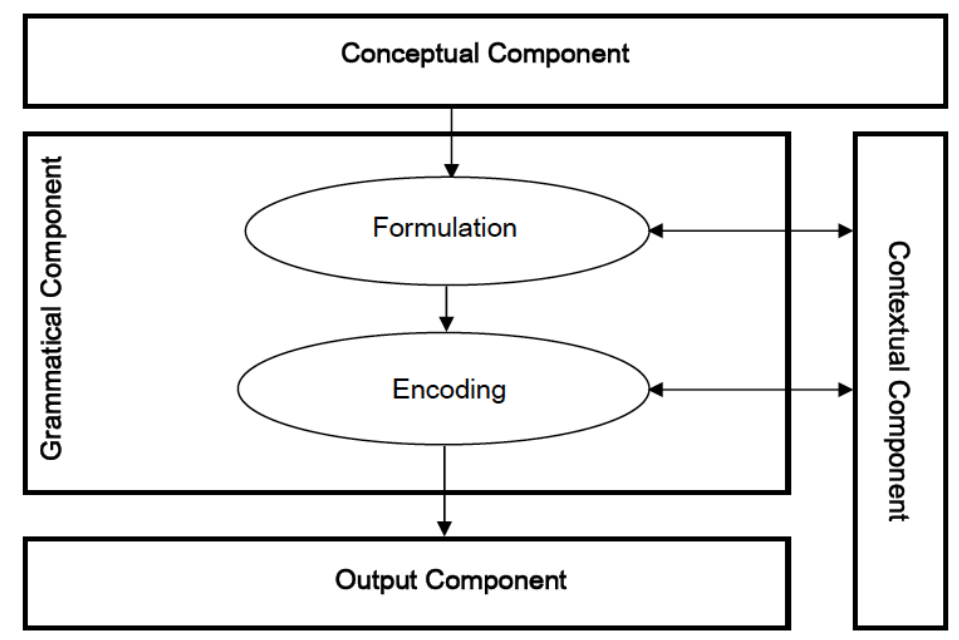

Figure 4. The Grammatical Component of FDG as Part of a Wider Theory of the Communicating Mind and Verbal Interaction: The functional Conceptual, Contextual, and Output Components (single-headed arrows: unidirectional input; double-headed arrows: bidirectional input)

Now, if Functional Discourse Grammar's “(discourse) grammar" is meant as an abstract(ed) declarative module that does not belong to any speaker-listener in particular, but to all or none, rather than a procedural processor within a wider theory of the communicating mind and verbal interaction, belonging to an abstract model of a Natural Language User, it seems to be illogical to speak of psychological and pragmatic adequacy of the FDG grammar model. The communicative intentions in the Conceptual Component are psychological facts of the psyches of concrete individual communicators. The phonetic articulations in the Output Component are physical facts of the real communicative behavior of actual speaker-listeners. And the situational context in the Contextual Component is a communicative reality. Furthermore, the processing constraints in grammars (e.g., word order regularities; see Hawkins, 2004) are adaptive structural consequences of actual performances, that is, of performance that has occurred in actual history. Actually, these facts about language structure are what motivated the epithet functional in Dik's original Functional Grammar model in the first place (Dik, 1997). 
Just as it is a category mistake to let the abstract grammatical module have a concrete input in the form of actual pragmatic communicative intentions, it is equally misguided to let this abstract, disembodied grammar module be connected with actual concrete phonetic articulations in the Output Component, and likewise be connected with the concrete textual and situational contexts of the actual communicative situation. To be compatible and coherent, the grammatical component has to be just as concrete and real (however idealized) as the other components, and like them it has to be procedural, rather than declarative. Therefore, the grammar model is an integral part of the wider theory of the communicating mind and verbal interaction, not an autonomous module. Otherwise, a psychological top-down model, like that of Levelt (1989), on which Functional Discourse Grammar bases itself, is irrelevant. The grammar model is abstract in the sense that linguistic science is nomothetic, striving for regularities. The regularities are immanent (Aristotelean), rather than transcendent (Platonic) - the model is monistic-realist, not dualistic-idealist. Communicative competence is embodied. This means that, even though it is social or interindividual, it is operative, functional, within the confines of the single individual's mind, brain, and body. For instance, individual mental illness may cause linguistic deficits (e.g., schizophrenia may cause psychotic speech); individual brain damage may cause linguistic injuries (e.g., aphasia); the amputation of an arm of an individual means amputation of manual-brachial gesticulation and thereby this modality of total communication. If the speaker-listeners of a given historical language (idiom) commit collective suicide, their communicative competences eo ipso no longer exist, and their language is dead and cannot be actively transmitted as a living tongue. ${ }^{12}$

On account of the above, a communicative competence, including its grammar, must be a procedural deontological know-how, rather than a declarative (transcendental) epistemic knowing-that of the language accessed by the performance systems (pace Zlatev 2011). A linguistic communicative competence is the verbal-symbolic capacity of a linguistic cyborg, on the one hand acquired and learned abductively on the basis of a biologically inherited language faculty and, on the other, further inductively developed on the basis of recurrent patterns in actual usage of the textual surroundings. Notice that the idiosyncratic iconic and indexical gestural parts of the symbolic language game are not in this way learned by guessing and public observation, but are more imitative and "home-grown". They must be the direct descendants of the iconic-indexical languaging and sign play evolutionary stages.

\subsection{Levelt's "computational” psycholinguistic processing model}

Functional Discourse Grammar strives to be psychologically adequate, as stated in the second quotation given in the previous subsection. However, the crucial fact is that it is only psychologically adequate in so far as the psycholinguistic model, by which it is warranted, is itself plausible. Functional Discourse Grammar, as just mentioned, seeks support in Levelt's (1989) psycholinguistic processing model, but this model may be contested since it sees linguistic processing as informational and modularized.

According to Levelt's (1989) "blueprint", language processing is modularized in the following way: The communicating mind consists of processors with an input-output

\footnotetext{
12 This would also be the case for a Saussurean transpersonal langue of the speech community: If the social body ceases to exist, its tacit external collective norms cease to exist too, and there would be no individuals to perform the parole and set linguistic change in motion.
} 
structure, and it produces informational representations, which are processed by these processors. In terms of top-down speech production, a conceptualizer takes communicative intentions as input and generates a preverbal message as output, which is taken as input to the formulator, which in its turn produces an internal lexicogrammatical surface structure. This morphosyntactic representation is phonologically encoded as a phonetic articulatory plan (internal speech), which is articulated as overt speech by the articulator. As his own listener, the speaker also receives his own speech (relevant in self-monitoring feedback), as does a separate receiver (e.g., intended as the addressee of the message). Reception then works backwards, or upstream, bottom-up: An auditive-phonetic processor takes the acoustic signal in and delivers a phonetic representation, which is phonologically and grammatically decoded, by a parser (i.e., analyzer), as a derived post-verbal message, the input to comprehension (discourse processing) in the conceptualizer. The final output is the inferred communicative intention, which may be compared (if we could get inside the speaker-listeners' talking heads) to the speaker's intention as otherwise displayed in the course of the conversation (cf. Figure 5, Levelt 1989, p. 9):

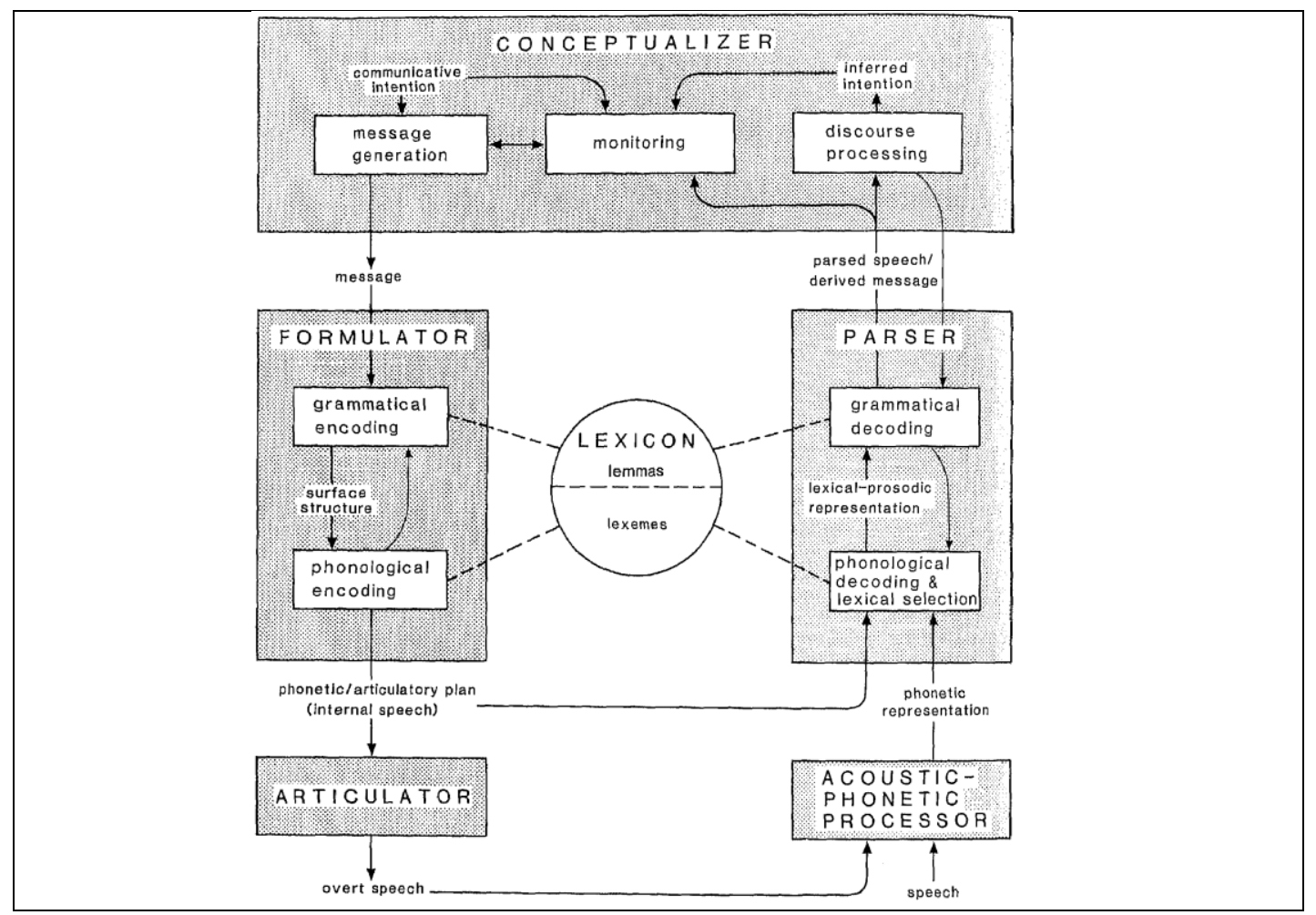

Figure 5. Blueprint of the Speaker-listener: From Intention to Articulation and Back Again (Notice the different cybernetic feedback loops, both in sending and in receiving, Levelt, 1989, p. 9.)

\subsection{Functional Discourse Grammar as a quasi-production model}

Levelt's procedural processing model of the speaker-listener is recast as a declarative grammatical model in a quasi-production model of the speaker (see Figure 4). The right- 
hand receiving modules are left out, as are the processes of feedback, in line with the intention not to be a psycholinguistic model. A crucial point of innovation is a Context Component. Hengeveld \& Mackenzie (2010) stipulate (our emphasis):

\begin{abstract}
- The Conceptual Component is responsible for the development of both a communicative intention relevant for the current speech event and the associated conceptualizations with respect to relevant extra-linguistic events, and is thus the driving force behind the Grammatical Component as a whole.

- The Contextual Component contains a description of the content and form of the preceding discourse, of the actual perceivable setting in which the speech event takes place, and of the social relationships between Participants. The Contextual Component is thus the discourse domain on the basis of which new utterances are produced in the Grammatical Component.

- The Output Component generates acoustic, signed or orthographical expressions on the basis of information provided by the Grammatical Component. Its function may be seen as translating the digital (i.e. categorical, opposition-based) information in the grammar into analogue (i.e. continuously variable) form.
\end{abstract}

It is important to notice that the content stratum of the Grammar Component in Figure 4 is divided into an Interpersonal Level formulating the communicative intentions in the Conceptual Component and a Representational Level formulating the representational content, which is derived partly from the Contextual Component, partly from the Conceptual Component. Note, too, that the expression stratum is likewise bipartitioned, namely into a morphosyntactic representation (next to the content) and a phonological representation, input to the phonetics. Note furthermore that in the model there is no contextual input to the Conceptual Component and no output from the Output Component to the Contextual Component (which is quite strange, given the fact that the acoustics is part of the input in language learning, cf. Andersen 1973). A last point to mention is that there is no input to the Contextual Component from the Conceptual Component. This is a lack in the model, since one may quite well react to the inferred intentions of the other conversationalist, as well as compare one's own original intention with what one manages to express, both in one's own interpretation and as inferred from the other's dialogical reactions. This is present in Figure 5, upper part. In all, Functional Discourse Grammar may be summarized as in the flow diagrams in Figure 6a (from Hengeveld \& Mackenzie, 2008) and 6b (from Hengeveld \& Mackenzie, 2014).

In Section 4 we integrated the three phases of language-speech into our model, namely the pattern phase, the process phase, and the product phase. Functional Discourse Grammar respects this tripartition, in that it comprises inventory boxes to the left in the diagram (pattern), processing ovals (formulation, encoding, articulation), and output rectangles (termed Levels). However, the model is deterministic, as seen in the diagram's only having input from the inventory to the processes. The model will thus only generate grammatical expressions, whereas in fact actual speech also includes both ungrammatical, innovatory, and creative usage. Note that a processor, Conceptualizer, is missing in the model that creates the Conceptual content. This processor would be the missing subject (as we mentioned above), the one responsible for the discourse acts, both for production and receiving, the one who is creative, in terms of invention and linguistic creativity. 


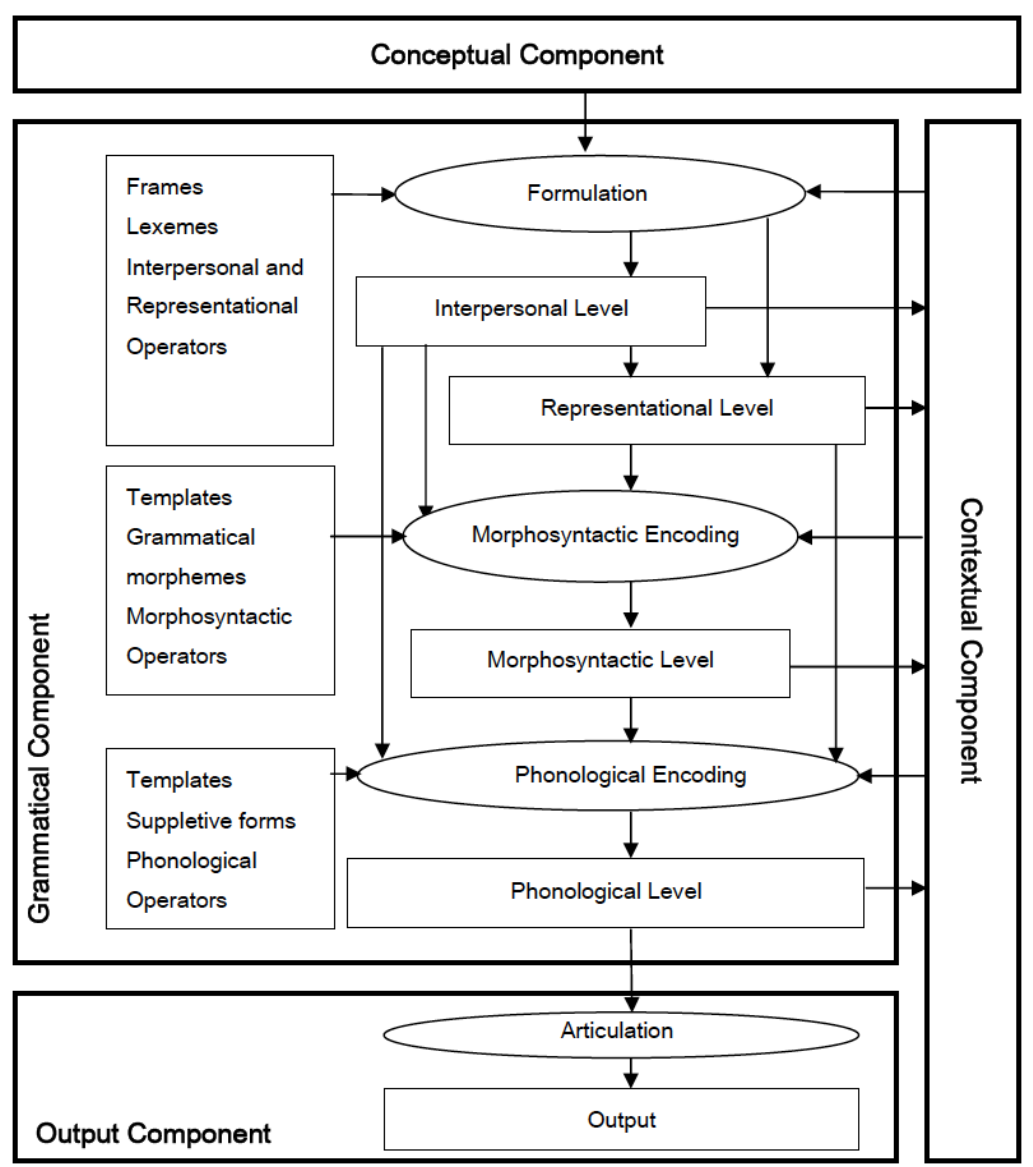

Figure 6a. General Layout of Functional Discourse Grammar (Hengeveld \& Mackenzie 2008, p. 13)

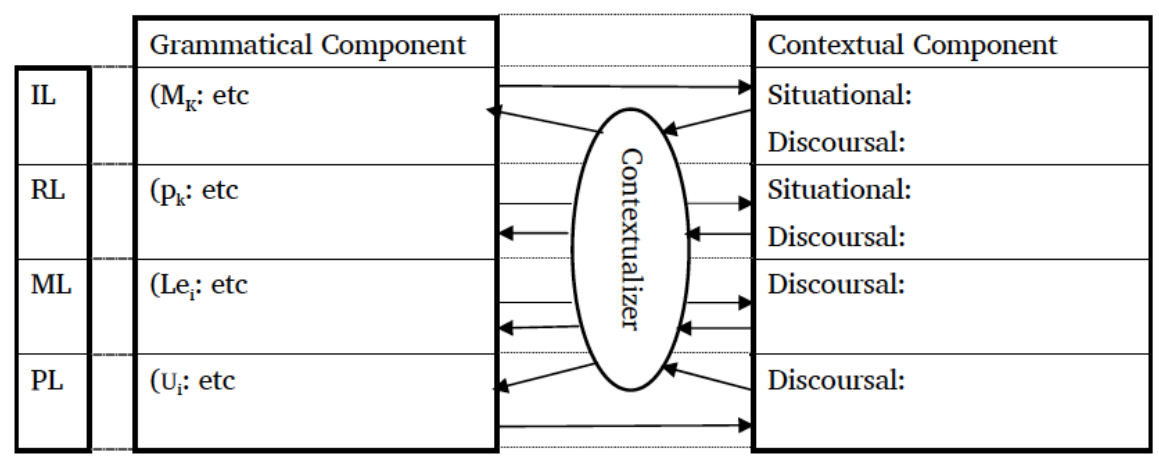

Figure 6b. The Contextual Component and the Contextualizer. There are four levels: Interpersonal Level (IL), Representational Level (RL), Morphosyntactic Level (ML), and Phonological Level (PL) 
Why is it that the Contextualizer is an interface processor between the Grammatical Component and the Contextual Component, when Formulation, Encoding, and Articulation all belong with a specific component (placed inside some box)? Coherence would require all processors to be interfaces, with Encoding being the sole component-internal interface. Another inconsistency is that there is no interface processor between the Interpersonal and the Representational Levels. We take this as a sign that they should be seen as two dimensions of one content level (comparable to the intentional-conceptual level of the Conceptual Component). A last difficulty about the model is that the Contextualizer does not interface the Contextual Component with the rest. Alternatively, the processors could be aligned with one component each: Formulation with the Conceptual Component, Encoding with the Grammatical Component (as at present), Articulation with the Output Component (as at present), and the Contextualizer with the Contextual Component.

With the requisite adjustments, the FDG model would be semiotically adequate, in terms of Peircean semiotics and Cybersemiotics. First, by integrating the Contextual Component, the model is triadic: Referential subject matter is not left out as it is in dyadic, Saussurean-based linguistics. Furthermore, extensional content is represented by the referential variables in the Grammar Component (not shown in Figure 6A). Intensional content is represented by predicates, predications, propositions, and clauses. Speaker's communicative intentions are present in the Conceptual Component. Lastly, phonetic or signed manifestation is present in the Output Component and would be correlated with acoustic signals in the Contextual Component. Symbolic conventions are dealt with by content frames and lexemes, combined with expressional templates and forms. Indexicality is viable via input from the Contextual Component into the Grammatical Component. However, the Contextual Component should also be input to the Conceptual Component. For one thing, the actual social relationships between the communicators may constrain the type of illocutionary point that a speaker may felicitously select or develop in the Conceptual Component-a social superior has quite different illocutionary possibilities from those of an inferior. For another, the physical and social surroundings are perceived and conceptualized and are accordingly input to the Conceptual Component (Chafe, 1977).

Functional Discourse Grammar is a model primarily of discourse, rather than sentence, the focus of traditional sentence grammars. This point of view is coherent with Peircean Cybersemiotics, where discourse-dialogue and other kinds of texts and holophrases - represent the highest rank of semioticity. FDG's discourse act corresponds to the middle rank; and the frames and lexemes of the Grammar Component correspond to the lowest, predicate rank.

A final comment: Noise is an important factor in a cybernetic model of communication and cognition and should thus also be integrated into a cybernetically and cybersemiotically adequate theory of language and will be so in Cybersemiotic Discourse Pragmatics. 


\section{Multimodality in a possible Functional Discourse Grammar}

\subsection{Kopp et al.'s Parallel Processing model}

Evidently, the Functional Discourse Grammar model only concerns the verbal part of the language game level, and there is no indication in its canonical version as to where nonverbal communication would belong. One, rather implausible, proposal is Connolly's (2010), where nonverbal communication is part of the Contextual Component. However, the speaker's gesticulation is evidently not the discourse context of his verbal utterance, even though it may be part of the attentional background of the communicative situation. A more plausible proposal (see Nedergaard Thomsen, 2010) would be the following: What there may be of iconic-imaginal content to be gesticulated in non-verbal communication on the level of language games would belong to the Conceptual Component. This component would then be a multimodal conceptualizer. Any formalstructural content and expression would then be coupled to the Grammatical Component. This may give rise to an integrated Gesture-Grammar Component, an integral system of semiotic codes, an inter-grammar (cf. Arndt \& Janney, 1987). And finally, the production of the sign vehicles of nonverbal communication would naturally belong with the articulator, accordingly now viewed as a multimodal articulator. In total, the multimodal communicative competence would adequately be an inter-pragmatics, a cybersemiotic discourse pragmatics.

There is some empirical evidence (Melinger \& Levelt, 2004) pointing in our direction: a trade-off between formulating a spatial description by way of iconic gesturing and formulating it verbally, whereby the more explicit the gestural depiction is, the more may be omitted in speech, and vice versa. Other studies indicate that, besides the communicative intention being verbalized at the Interpersonal Level, only the propositional-ideational part of conceptualization is input to verbal formulation.

The conceptualizer may comprise several, mutually interacting representational systems: spatial, propositional, kinesthetic, and other. Insofar as only the propositional system is input to verbal formulation, the other kinds of content then must have an outlet in the non-verbal expressional modalities (see Figure 7).

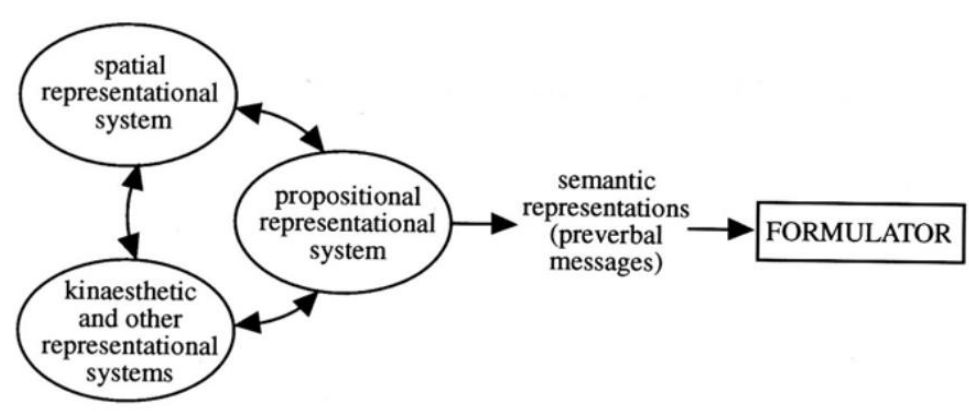

Figure 7. The Propositional Representational System Yielding Preverbal Messages as Input to Verbalization (Encoding). The spatial, kinaesthetic, and other representational systems are input to nonverbal gesticulation.

Kopp, Bergmann and Wachsmuth's (2008) computational model captures gesticulation in the way we have just sketched. Thus, multimodal language games 
involve multimodal thinking for multimodal communicating in a general-purpose processing system (cf. Figure 8).

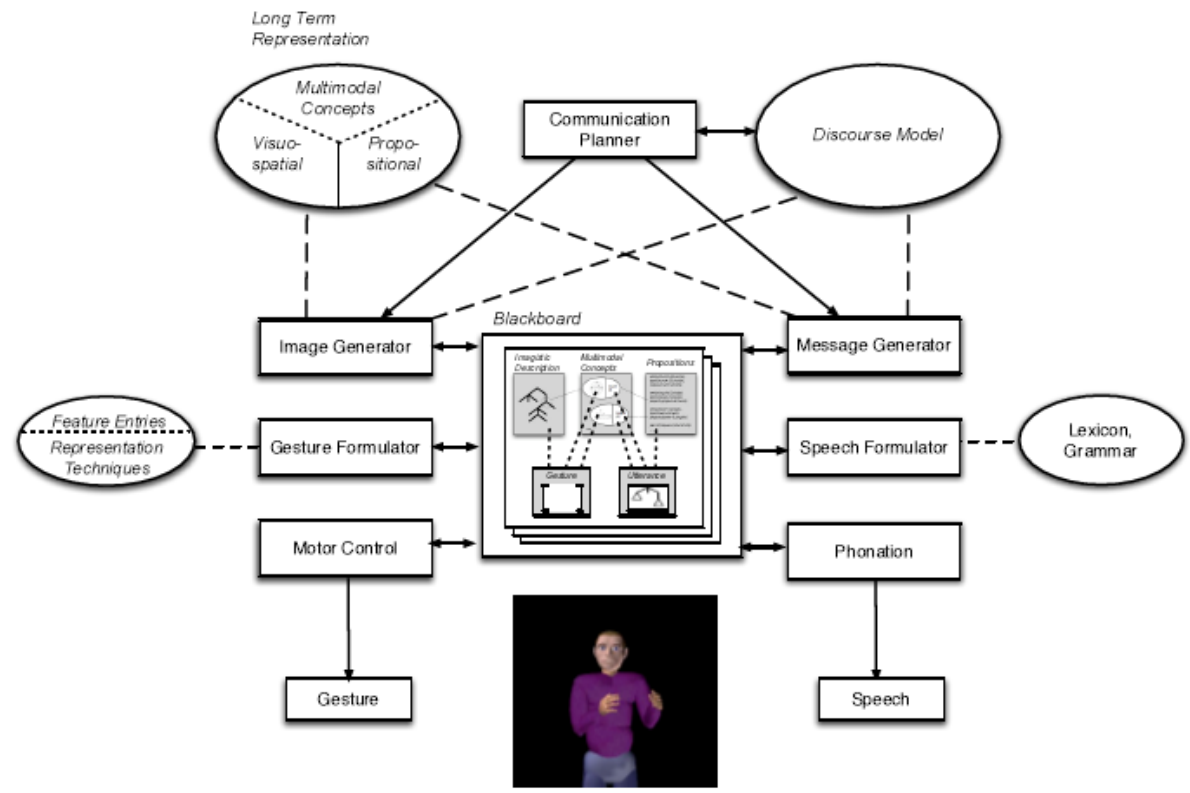

Figure 8. Kopp et al.'s (2008) Model of Multimodal Thinking for Multimodal Communicating

In this model the communication planner (upper middle), the multimodal concepts (upper left), the discourse model (upper right), and the image and the message generators (left and right below) would correspond to a conceptualizer. Notice that the model is discourse centered, cf. the Discourse Model component. An inter-grammar would be the integration of the gesture formulator (with the gestural code) and the speech formulator (with the verbal code). Our multimodal articulator would then be the integration of motor control and phonation and the output the integration of gesture and speech as multimodal text. The visuo-spatial concepts are communicated iconically-analogically, by way of manual gestures. The blackboard, a workspace for integrating verbalization and gesticulation, is a central organizer (cf. Buck 2002).

\subsection{McNeill's Dialectical Microgenesis model}

An alternative, non-modularized, non-computational model is McNeill's (1992, 2005, 2006) dialectical microgenesis model, where gesture and speech are characterized as in Table 2. 
Public Journal of Semiotics 6 (1)

Table 2. Characteristics of Gestures and Speech According to McNeill's Microgenesis Model

\begin{tabular}{|c|c|}
\hline Stage 1: Iconic gestures & Stage 2: Symbolic speech \\
\hline 1. spontaneous, unwitting & 1. premeditated, intended as symbolic \\
\hline 2. imagistic form of thought (imagery) & 2. symbolic-categorial form of thought \\
\hline 3. conceptual (qualitative) & 3. propositional-discoursal \\
\hline $\begin{array}{l}\text { 4. idiosyncratic, not codified, holophrastic } \\
\text { unstructured whole; no gesture Lexicon }\end{array}$ & $\begin{array}{l}\text { 4. socially regulated, codified, hierarchically } \\
\text { structured string; morpheme Lexicon }\end{array}$ \\
\hline 5. motivated, non-idiomatic semiosis & 5. idiomatic, conventional semiosis \\
\hline 6. no dual pattern: meaning $\rightarrow$ kinesic form & 6. dual pattern: meaning $\rightarrow$ phonetic form \\
\hline $\begin{array}{l}\text { 7. non-standardized, non-distinct forms, no } \\
\text { structural correctness (well-formedness) }\end{array}$ & $\begin{array}{l}\text { 7. standardized, distinct forms, structural } \\
\text { correctness (well-formedness) }\end{array}$ \\
\hline 8. multidimensional (space: visual) & 8. unidimensional (time: auditory) \\
\hline $\begin{array}{l}\text { 9. analog: non-linear, non-hierarchical, non- } \\
\text { combinatoric, non-recursive }\end{array}$ & $\begin{array}{l}\text { 9. digital: linear-segmented, hierarchical, } \\
\text { combinatoric, recursive }\end{array}$ \\
\hline 10. instantaneous display of mental content & 10. temporally extended, successive coding \\
\hline $\begin{array}{l}\text { 11. global (whole determines meanings of } \\
\text { parts), coordinative structures, no syntax }\end{array}$ & $\begin{array}{l}\text { 11. compositional (meaning of whole is co- } \\
\text { determined by parts), combinatory syntax }\end{array}$ \\
\hline $\begin{array}{l}\text { 12. synthetic (one gesture can combine many } \\
\text { meanings synthetically and equivocally) }\end{array}$ & $\begin{array}{l}\text { 12. analytic (distinct meanings attached, one-to- } \\
\text { one, to distinct words and morphemes) }\end{array}$ \\
\hline
\end{tabular}

Here, the level of the language game is a two-phase process rather than the integrated parallel processes dealt with above (cf. the two sides of figure 8). Thinking-forcommunicating (cf. Slobin's 1987 thinking-for-speaking) is multimodal and developed, in a multimodal conceptualizer, in two complementary modes, an idiosyncratic-gestural and a conventional-verbal. They trigger a single integrated process of utterance formation (in the intergrammar), again instantiated in two, partly synchronized phases of coexpressive modes of representation:

Gesticulation: idiosyncratic spontaneous imagistic-iconic holophrastic gesturing

Verbalization: conventional premeditated propositional-symbolic syntactic speaking

The two phases are synchronized in a convergence of a gestural stroke (pulse peak) and a prosodic peak via a shared rhythmic pulse. This dialectical "knot" of imagery and categorical-propositional content is the so-called growth point in the thinking-forcommunicating (McNeill \& Duncan, 2000), starting the process of disentangling the two threads: gesticulating the content as well as propositionalizing it verbally. The Growth Point is a focal psychological predicate, differentiated from its context. A discourse 
segment is defined by thematic continuity and is gesturally formulated by so-called catchments of recurring similar gestures. Up to the Growth Point, in a so-called gestural preparation part, the gestural phase anticipates the verbal phase. In this way the dialectic of the utterance generation of a language game takes its departure in global (whole $\rightarrow$ part) iconic imagery, which is then taken over by the combinatory (part $\rightarrow$ whole) propositional-symbolic sentencing, which finalizes the formulation. The utterance is an integrated iconic-indexical-symbolic gesture-speech complex, the course of which is a dialectical process:

Thesis: image, iconic-indexical preparatory phase (gesture, rhythmic pulse)

Antithesis: symbolic propositional content (speech, rhythmic pulse)

Synthesis: convergence, synchronization (Growth Point: gestural pulse peak and verbal prosodic peak): integrated iconic-indexical-symbolic utterance

In terms of Peircean semiotics, this integration is straightforward: the gestural sublevel primarily concerns imagery predicate content, the verbal sublevel categorial propositional content as well as discourse content. The correlated expressions are, correspondingly, primarily iconic-indexical versus symbolic, respectively. McNeill's theory of the microgenesis of the utterance, asserting that the convergence of the gestural peak and the linguistic peak represents a communicative focus, a point from where the utterance grows, may be more compatible with a Peircean and systemic approach like Cybersemiotics than the computational-algorithmic models in Section 7.1.

\section{Towards a Cybersemiotic Discourse Pragmatics}

We are now in a position to round up what we are attempting to accomplish theoretically. Part of Cybersemiotics must be a cybersemiotic discourse pragmatic theory of human inter-subjective communication, conceived of as an integrated exosemiotic process of dialoguing: primitive reflexive languaging, instinctual-motivational sign games, and premeditated intentional symbolic language games, the latter integrating gestural iconicindexical as well as symbolic threads. Thus, it is a multimodal discourse process, protoor archetypically a face-to-face dialogue, governed partly by the multimodal communicative competences of the conversationalists, partly by their collective and individual communicative intentions and their expressive creativity. It results in coproduced multimodal texts, with a texture of threads corresponding to the different levels and sublevels of communication.

According to Cybersemiotics, communication is characterized by contextsensitive, incremental microgenesis responding to communicative intentions (pragmatic points) in thinking-for-communicating. The process of the symbolic language game is premeditated and top-down, from the communicator's global collective discourse intention of, for example, co-performing a whole interview with his interlocutor, to his local individual speaking-turn intention of, for instance, performing the discourse act of a question initiating the interview (cf. the particular level of abstraction in Table 1 Section 4). It is thus, from the point of view of the single turn or discourse act, characterized by looking ahead and preplanning. However, it is also co-determined from below, by reflexive languaging and species-specific, instinctually-based sign plays. Total evolutionary communication is accordingly the result of an integration of a "talking head", from above, and a "communicating body", from below, into a whole hybrid 
natural-nurtural linguistic cyborg. The language game includes the levels below and is in part determined by them - it is second-order nature (cf. Richerson \& Boyd 2001).

The Cybersemiotics model is second-order cybernetic, with all sorts of selfmonitoring, loops, and feedback, among which speaker's feedback from formulation to conceptualization (reconceptualization) in cases of felt infelicitous formulation.

Cognition and communication, as just said, involve the communicator's individual as well as collective intentionality (Searle, 1990; Tomasello, Carpenter, Call, Behne \& Moll, 2005). The individual intentionality of the discourse act is enacted on the background of the presupposed collective intentionality defining the whole communicative interaction. For instance, I perform my answering your question as a coherent part of our interview, you being the interviewer, I the interviewee.

We have claimed many times that total communication is constrained by global joint (shared, collective) we-intentions, in addition to the local individual I-intentions. Note that both kinds of intentions are intentions of the single communicators individually, and notably the former not an intention of a collective social body (supermind) like a communicative dyad, as a unity. Your communicative move (e.g., interview question) is thus a constitutive part of the totality of our joint conversing (e.g., our playing the interview game together), and, reciprocally, my communicative move (e.g., answering) is a constitutive part of the same co-played language game. The language game is a collective totality, a collaborative achievement. In the mind of the single communicator it is a final cause, a global discourse entry condition for his constitutive local dialogue moves, his parts of the intended game. That is, first the language game is present virtually, as a "distributed" collective intention, then it is incrementally and progressively enacted by the individual communicators performing their respective constitutive turns (governed by their simultaneous individual communicative intentions), and finally it is realized as a total collective or joint achievement - a physical and social fact: a palpable cybersemiotic text (registered in the Contextual Component and used as discourse domain).

In the same vein, language is primarily an individual communicator's communicative competence. Basically, it is an idio-lect, a private possession, but by having a social-public scope, it is simultaneously a dia-lect - it is a symbolic convention claimed to be shared by others within the same we-group. The language of the speech community, e.g. the idiom of the national macro we-group, may be conceived of as a collective social institution (Searle, 2010), as is the universal linguistic faculty, the linguistic institution of humankind. It is a virtual achievement, a summation not realized as such, only "distributively" in the single individual's "additive" dialects.

We are now drawn back to our leitmotif of the complementarity between cognition and communication as individual versus collective phenomena. On the one hand, cognition and communication are individual accomplishments: Even attempts at cocognition and social intercourse are ultimately based on individual intentions, as stressed. On the other hand, it may be equally evident that cognition and communication are not what they are except in their communal forms (Luhmann, 1995). Therefore, we speak of cognition and communication as socio-culturally virtually distributed over/between the individuals (see Hutchins, 1995). In the end, it may be a question of complementarity (Bohr, 1961). From the point of view of a participant observer, we may be forced to accept methodological individualism (but not solipsism) with a subjective basis. 
However, from a more subject-detached, objective viewpoint, hovering above the individuals (like a biological observer of an anthill), we may be forced to accept methodological collectivism. Presently, we stress the former point of view (cf. Maturana \& Varela, 1980), whereas standard Cybersemiotics (Brier, 2008) vouches for a model that integrates both perspectives as different levels of reality (which may be more Peircean in spirit).

Communication and communicative cognition - human total communication-is not only distributed in the three evolutionarily motivated modal stages, but also in its physical-material-instrumental manifestations, its media: Communication, besides being multi-modal, is also multi-medial and may involve, for example, writing, oral language, and pictorial manifestations in the same discourse (e.g., a teacher using a blackboard, a map, and a pointer). The principal distinction is here between the primary audio-visual media of communication: auditory vocal language vs. visual sign language. Pictorial as well as musical communication are examples of media that may be part of the same communicative situation and intention in total communication, for example in theatrical performances and educational demonstrations. Multi-modality is a characteristic of the different medial languages, e.g., facial expressions in sign language. Writing is a secondary visual medium that can be used to represent diagrammatically both oral and signed language, as well as, for instance, formula writing in mathematics, linguistics, and algebraic logic. Medium is crucial in the understanding of communication as embodied, as part of physics, of biological evolution, and of cultural development.

The notions of distributed cognition and distributed language may be used to capture the fact of the sociality or collectivity of cognition and communication. As is made clear throughout, we do not thereby want to discard the individuality and subjectivity of these maybe basically intersubjective phenomena. Rather, as we said above, it might be a question of complementary descriptive viewpoints, not of the explanatory essence or ontology of the phenomena. We may go the whole hog, as in distributed cognition theory, and speak of even intra-personal cognition (reflection, understood as an inner dialogue with one's alter ego) as distributively embodied subindividually among the functional components in the neural society of the brain. In the opposite, macroscopic, supra-individual, sociological dimension, cognition is socially distributed, in collective language games, and culturally embedded-it projects into a cultural signification sphere. However, we may also conceive of sociality and the extended and distributed phenomena as individually-based and emergent, not as autopoietic but rather as sympoietic, as claimed at the beginning of this article.

\section{Widening the Cybersemiotic Discourse Pragmatic perspective}

An essential perspective lacking in Functional Discourse Grammar is the integration of the practice of communication with the practice of living, of language games with life forms, and of the communicative competence with general socio-cultural competences (cf. Andersen, 1991), as understood in Wittgensteinian pragmatics (Wittgenstein, 1953).

A crucial step in evolution was the mimetic mind and culture, characterized by representational and re-enactional intentionality (Donald, 1991; Nelson, 1998), the use of fire to cook food, and the institution of communion, the sharing of food among family members. Here originated phatic communion (the contact function) and the development 
of symbolic-conventional codes (the contract function). ${ }^{13}$ Mimesis can be seen as the outgrowth of the primary, proto-semiotic, reflexive stage of languaging and the general primate episodic mind and culture, securing coordination and community (see Donald, 1991). Mimesis is a precursor to the symbolic stage, or its zero starting point. It has a social, communicative, re-enactment side and an individual, cognitive, re-presentational side. Mimesis is evidently an advanced form of iconicity. Its stages would be from images, over diagrams, to metaphors. Metaphoricity would include narrativity, which is the characteristic of the next, mythic stage of Homo sapiens (Paleolithic epoch, Stone Age) in Donald's evolutionary theory. A myth comprises a model of the world. Narrative skills are a fundamental part of the communicative competence of modern man. Narrative thinking (mythos) is prior to paradigmatic thinking (logos, analytic thought), the characteristic of the theoretic mind and culture that involve prediction and scientific explanation (Homo sapiens sapiens). In terms of Peircean semiotics, the differentiation between narrative thinking and syllogistic thinking amounts to a classification of types of argumental interpretants, where narration would be diagrammatic (episodic representation; Jakobson 1965). Here we seem to have reached the final, oral symbolic stage of language games, the endpoint of the biological evolution of modern language as we know it. From here on, everything is history, as they say, cultural and languagespecific history. The linguistic cyborg is now not only a biological organism, but also a socio-cultural person and a Homo faber (technological man). This means that he is able to extend and amplify his body-mind prosthetically through various forms of communication technology. For instance, his internal mental vocabulary (biological memory for words) and encyclopedic network of propositional knowledge may now be supplemented by external, collectivized written and digital dictionaries and encyclopedias. His unwritten norms may be supplanted by written law. That is, he has at his cognitive disposal external symbolic storage and retrieval systems.

Our concluding note is that the crown of evolution is the development of the hybrid, bio-technological mind and the information, knowledge, and communication technologies that amplify the cognitive reach of Homo sapiens vel communicans to unforeseen heights and horizons.

\section{Prospect: Emotions and beyond}

The role played by the second, instinctual-motivational-emotional stage in total evolutionary communication is not well understood (and not part of Section 9). Emotion, routines, and rituals as expressed in sign plays, have been out of focus in the linguistic models of communication up until now-their focus has mainly been on ideational and interpersonal cognition. Nevertheless, emotions were already considered essential for communication by ancient rhetoric, by Darwin (1872), by Jakobson (1960), and later by

\footnotetext{
${ }^{13}$ Roman Jakobson (1960) recognizes six factors of the communication situation and derived from them six functions of a given communication process. Defined in relation to sending and receiving a message, we have a sender (addresser) and an addressee. A precondition for communication to take place is a psychophysical contact between them (psychological connection, or empathy, and physical-medial reach). A second precondition is that the message is encoded and decoded according to more or less shared semiotic codes (conventions). The codes provide the communicators with requisite emic semiotic means for their communicative behavior, in terms of both content and expression, and their semiotic interrelation. A focus on the code (reflexivity) is the metalinguistic function, prerequisite for language transmission and change.
} 
ethologists (e.g., Eibl-Eibesfeldt, 1970, 1973). According to Damasio (1994, 1998, 2000), embodied emotions and feelings have a survival value and are crucial for creativity and rationality. Also for Maturana and Varela's autopoiesis theory (Maturana \& Varela 1980), emotions are a sine qua non: Emotioning, according to Maturana, is an essential ingredient of conversation. It is a view taken up lately by Maturana in his biology of love (see Maturana \& Verden-Zöller 2008[1996]). It is reminiscent of ancient oikeiosis (self and other preservation) and Peirce's principle of agapism, or "evolutionary love" (Peirce 1923[1998]). According to Maturana and Verden-Zöller:

Love ... is the domain of those behaviours or dynamic body dispositions through which another [person] arises as a legitimate other in coexistence with oneself ... through which social life arises and is conserved; it is simply the biological dynamics that constitutes trust and mutual acceptance in body and spiritual relations of nearness and intimacy. ... as body dynamics ... that specify at any moment in what relations we can enter at that moment. (Maturana \& Verden-Zöller, 2008[1996], p. 41)

Embodied emotions and "love" (trust and mutualism) are the basis of cooperation necessary for language games to function (cf. Grice's well-known "cooperative principle") - and derivatively for communities and societies to (come to) exist (to make man a zoon politikon, a "political animal").

All this needs to be integrated into our understanding of total multimodal evolutionary communication. The motivational part of the sign plays is the input to the conative function of language games (Jakobson's focus on influencing the addressee), the things you can do and get done with words. The prerequisites for the referential function of communication, in the form of shared attention, are investigated by Tomasello and his associates, but the actual evolution and development of linguistic-symbolic indexicality, of "shifters", are not well understood. A glaring lack in linguistic communication theory, and functional linguistics in general, is the rhetorical-poetic discourse function of language games. Here again Darwin, with his musical-prosodic protolanguage theory stressing sexual selection (Darwin, 1871), is a good starting point. He proposed that language arises in musical duetting (cf. Fitch, 2010) and stressed the role of vocal imitation or mimesis. ${ }^{14}$ According to Peircean semiotics, aesthetics is foundational. Classical functionalism (Jakobson 1987, 1990; Coşeriu 1977) represents an understanding of language and its poetic-creative function as coextensive, and even, with Coşeriu, as all-comprehensive, other "uses" of language, from ordinary conversation ("general purpose") to scientific language ("special purpose"), being reductions (automaticization, conventionalization). This is coherent with the classification of language as energeia, as creative interactivity (poiesis), with the norms and conventions being guidelines, not determinants.

Lastly, we still do not understand exactly the evolution and development of symbolic codes and conventions. Insofar as Peirce understands symbol and symbolic behavior as habit, even the ethological level of sign plays with their conditioned behavioral routines may be understood as symbolic, but then what is the exact difference between the symbolic conventions of language games and the habitual ethological behaviors? Here we may look at the evolution and development of deontological

\footnotetext{
${ }^{14}$ Rather than sexual selection, the universal musical function seems to be in mother-infant communication (lullabies and play songs; cf. Fitch, 2010), possibly an epigenetic-cultural development.
} 
Public Journal of Semiotics 6 (1)

commitment and morality, including discourse ethics: the inherited (so we believe) feeling of obligation to follow shared rules.

The final integration, to make the picture totally total, concerns the wholesale organismal-personal semiotic system that also, in addition to the exosemiotic levels of languaging, sign plays, and language games, contains all sorts of internal semiosis going on in a communicating individual (possible input to exosemiosis), as well as environment-related eco-semioses creating the individual (and derivatively, cultural) Umwelts and signification spheres of the communicators understood as linguistic cyborgs.

\section{Appendix A. The Cybersemiotic Star (Brier, 2008)}

Human beings are embodied, feeling, knowing, and culturally formed, participating in semiosis and language processes. They live simultaneously in four different worlds, listed below and shown in Figure 9.

1. The physico-chemical part of the natural world that also constitutes the pure materialenergetic aspect of our body.

2. Our embodiedness as the source of life, which we share with other living species. It is a product of ecology and evolution, but also formed by cultural practices.

3. Our world of feeling, will, drives, affects, and thoughts, manifested as mind, consciousness, and self-consciousness. We think it is partly produced by our embodied nervous system and formed by culture, most strongly during our childhood.

4. The cultural world of language, meaning, power, and technology, such as the informational machines we call computers. Language, pragmatically conceived, connects our perception with our thinking, communication, and acting in the social world.

Each of the four worlds has developed its own type of narrative, with its own fundamentalist and reductionist versions, vitiating the project of transdisciplinarity. Physicists and chemists tend to view the universe as consisting of matter, forces, and energy. Mechanistically oriented biologists extend this view into their subject area. However, non-mechanistically oriented biologists perceive living systems as the basic organizers of reality, possessing self-organizing, self-protecting, selfpromoting, and reflective properties as well as perception, instincts, and communication. This view of life as a foundational quality means that the natural and the life sciences are distinct.

The social and cultural sciences, especially dialectical and historical materialistic perspectives as well as the radical social constructivist ones, see the world as constructed from social, human, and linguistic interpretations, unless they are dualistic, accepting that nature is just as science describes it. Thus, energy-matter-information, life, consciousness, and meaning become separated in four different worlds, which is in conflict with our everyday life world experience, where they are not in any way absolutely separated. Thus we lack a transdisciplinary, "scientific" explanation of how they are integrated. 


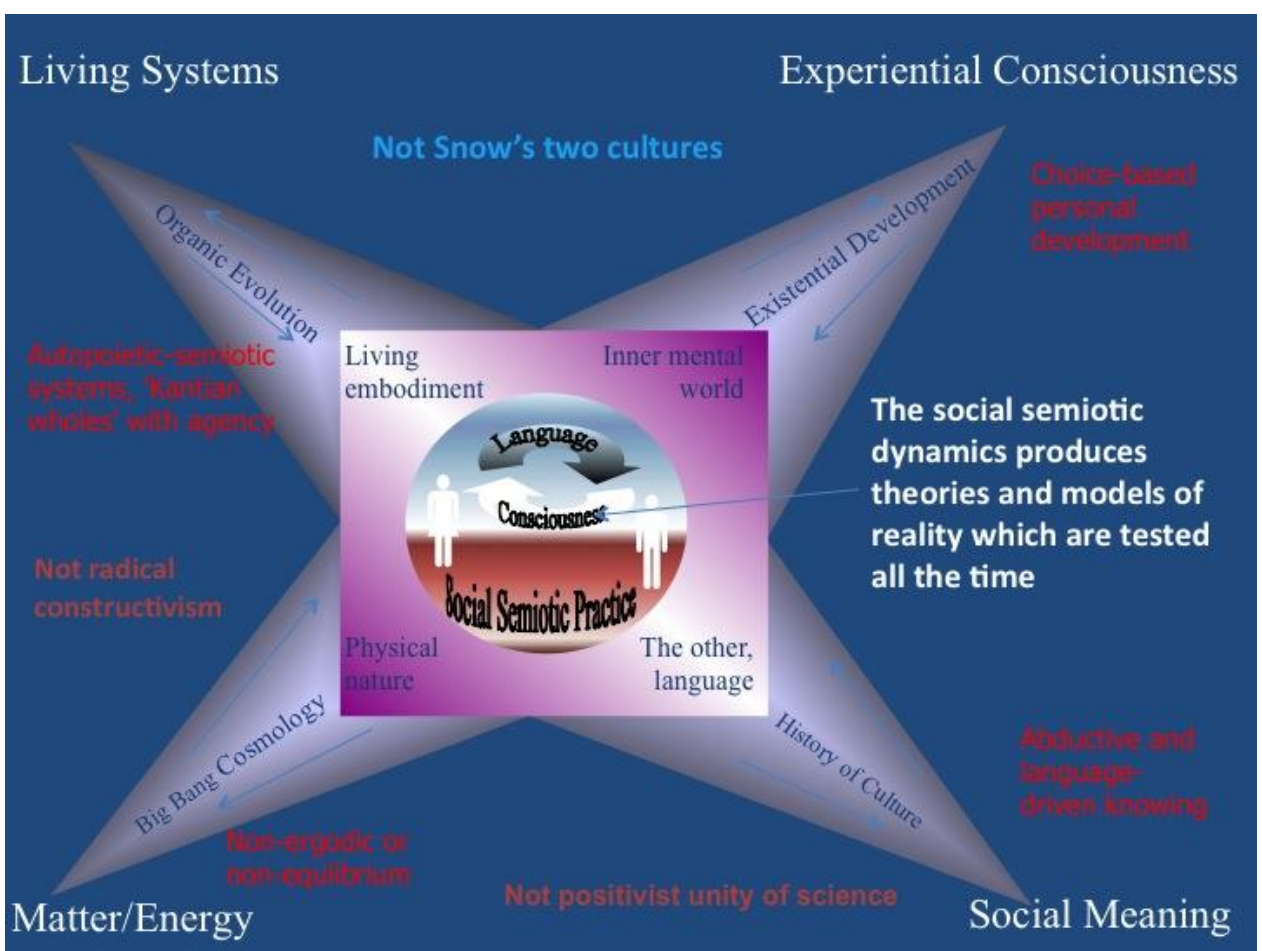

Figure 9. The Cybersemiotic Star: Cognitive-communicative social systems produce four main areas of knowledge. All these types of knowledge, considered incommensurable, have their origin in our primary semiotic intersubjective life-world processes of observing and interpreting based on social linguistic communication and action. The arrows inside the arms of the star pointing in opposite directions signify that the interpretations and explanations of the worlds are produced intersubjectively and tested empirically by falsification procedures. Those interpretations and explanations that fail return into socio-communication's semiotic net and are revised and thereafter tested again in an ever-ongoing process of developing knowledge and skills.

One of the reasons for the separatist tendencies of the received views of natural and social sciences as well as the humanities may be that their traditions of science were established before the theory of evolution became broadly accepted. Thus, the incompatibility of these four dominant views in the systematization of knowledge is a deep paradox in the modern attempt to build a "unified narrative" of the world. This is especially so since it has been broadly accepted in all four "worlds" that the "unity of science" idea of the logical positivists failed because it was predicated on the excessively narrow epistemological foundation of verificationism. Popper's argumentation for a falsificationist view of scientific knowledge has been accepted as a turning point in the break with the positivist unity of science, but not as providing any final solution to the problem. Kuhn's work on paradigms and their incommensurability has been generally accepted by philosophers of science and many scientists, changing the mono-paradigmatic view based on the history of the natural sciences, into an acceptance of parallel co-existing paradigms, especially in the realm of the social sciences and humanities. This view has been extended to include the social and the life sciences in order to put all forms of Wissenschaft on an equal standing. Cybersemiotics is built on absolute naturalism, which is a necessary prerequisite for establishing a non-reductionist transdisciplinary view. Cybersemiotics organizes the sciences and humanities differently from 
anything that has been done before, by integrating Peircean semiotic pragmaticism with Luhmann's triple autopoietic systems theory (Brier 2008, 2013).

\section{Acknowledgements}

Thanks to our two anonymous referees for very valuable comments and criticisms, both as regards content, style, and argumentation. Without these, we would have contributed an inadequate paper. Also thanks to Jordan Zlatev for his always painstaking critique, and to a copy-editor from the Public Journal of Semiotics.

\section{References}

Andersen, H. (1991). On the projection of equivalence relations into syntagms. In S. Rudy and L. R. Waugh (Eds.), New vistas in grammar: Invariance and variation (pp. 287-311). Amsterdam: Benjamins.

Armstrong, D. F., Stokoe, W. G., \& Wilcox, S. E. (1995). Gesture and the nature of language. Cambridge: Cambridge University Press.

Arndt, H., \& Janney, R.W. (1987). InterGrammar: Toward an integrative model of verbal, prosodic, and kinesic choices in speech. Berlin: Mouton de Gruyter.

Bloch, B. (1948). A set of postulates for phonetic analysis. Language, 24(1), 3-46.

Bohr, N. (1961). Atomic theory and the description of nature. Cambridge: Cambridge University Press.

Brier, S. (1995). Cyber-semiotics: On autopoiesis, code-duality and sign games in biosemiotics. Cybernetics and Human Knowing, 3(3), 3-25.

Brier, S. (2003). Information seen as part of the development of living intelligence: The five-leveled Cybersemiotic Framework for FIS. Entropy, 5, 88-99.

Brier, S. (2006). The missing person: Problems in reflecting Luhmannian empirical systemic research results: Back into a democratic society of embodied, juridical, political and ethical responsible subjects. In ISA-International Sociological Association, XVIth World Congress of Sociology, The Quality of Social Existence in a Globalizing World. Durban, South Africa, July 23-29, 2006.

Brier, S. (2007). Applying Luhmann's system theory as part of a transdisciplinary frame for communication science. Cybernetics and Human Knowing, 14(2-3), 29-65.

Brier, S. (2008). Cybersemiotics: Why information is not enough. Toronto: Toronto University Press.

Brier, S. (2013). Cybersemiotics: A new foundation for transdisciplinary theory of information, cognition, meaningful communication and the interaction between nature and culture. Integral Review, 9(2), 220-263.

Buck, R. (1988). Human motivation and emotion (2nd ed.). Oxford, England: John Wiley $\&$ Sons.

Buck, R. (2003). Emotional experience, expression, and communication: A developmental-interactionist approach to biological and higher-level social, cognitive, and moral emotions. Paper presented at Yale University Emotion Interest Group.

Part 1: URL:

http://coms.uconn.edu/directory/faculty/rbuck/presentations/MECdefs03_files/frame.htm Part 2: URL: 
Nedergaard Thomsen and Brier

http://coms.uconn.edu/directory/faculty/rbuck/presentations/EmotDev03_files/frame.htm

Buck, R. \& VanLear, C. A. (2002). Verbal and nonverbal communication: Distinguishing symbolic, spontaneous and pseudo-spontaneous nonverbal behavior. Journal of Communication, 52(3), 522-541.

Chafe, W.L. (1977). The recall and verbalization of past experience. In R. W. Cole (Ed.), Current issues in linguistic theory (pp. 215-246). Bloomington: Indiana University Press

Chomsky, N. (2007). Biolinguistic explorations: Design, development, evolution. International Journal of Philosophical Studies, 15(1), 1-21.

Clark, A. with D. J. Charmers (1998). The extended mind. Analysis, 58(1), 7-19.

Connolly, J. H. (2010). Accommodating multimodality in functional discourse grammar. Web Papers in Functional Discourse Grammar/WP-FDG, 83, 1-18.

Coseriu, E. (1955-56). Determinación y entorno. Romantisches Jahrbuch, 7, $24-54$.

Coseriu, E. (1977). Tesis sobre el tema "lenguaje y poesía". In E.Coseriu, El hombre y su lenguaje (chap. 8). Madrid: Gredos.

Coseriu, E. (1980). Der Sinn der Sprachtypologie. In T. Thrane, M. Winge, L. Mackenzie, U. Canger, and N. Ege (Eds.), Typology and genetics of language (pp. 157-170). (Travaux du Cercle Linguistique de Copenhague, 20.) Copenhagen: The Linguistic Circle of Copenhagen.

Coseriu, E. (1985). Linguistic competence: What is it really? Modern Language Review, 80(4), 25-35.

Coseriu, E. (1992). Competencia lingüística. Elementos de la teoría del hablar. Madrid: Gredos.

Cowley, S.J. (2011). Taking a language stance. Ecological Psychology, 23(3), 1-25.

Cowley, S.J., et al. (2014, Guest Eds.). Cybernetics and Human Knowing, 21(1-2).

Damasio, A. (1994). Descartes' error: Emotion, reason, and the human brain. New York: Grosset/Putnam.

Damasio, A. (1998). Emotion in the perspective of an integrated nervous system. Brain Research Reviews, 26(2-3), 84-86.

Darwin, C. (1871). The descent of man, and selection in relation to sex. London: John Murray.

Darwin, C. (1872). The expression of the emotions in man and animals. London: John Murray.

Deacon, T. (2012). Beyond the Symbolic Species. Biosemiotics, 6, 9-38. (T. Schilhab et al. (Eds.), The Symbolic Species Evolved. No place: Springer.)

Dempster, M. B. L. (1998). A self-organizing systems perspective on planning for sustainability. Master's Thesis of Environmental Studies in Planning. Waterloo, Ontario, Canada: University of Waterloo, School of Urban and Regional Planning.

Dik, S. C. (1997). The theory of functional grammar (parts $1+2$; K. Hengeveld, Ed.). Berlin: Mouton de Gruyter.

Donald, M. (1991). Origins of the modern mind: Three stages in the evolution of culture and cognition. Cambridge, MA: Harvard University Press.

Eibl-Eibesfeldt, E. (1970). Ethology: The biology of behavior. New York: Holt, Rinehart and Winston.

Eibl-Eibesfeldt, E. (1973). Der vorprogrammierte Mensch. Vienna: Fritz Molden. 
Fawcett, R. P. (1983). Language as a semiological system: A re-interpretation of Saussure. In J. Morreall (Ed.), The Ninth LACUS Forum 1982 (pp. 59-125). Columbia SC: Hornbeam Press.

Fitch, W.T., Hauser, M.D., \& Chomsky, N. (2005). The Evolution of the language faculty: Clarifications and implications. Cognition, 97(2), 179-210.

Fitch, W.T. (2010). The evolution of language. Cambridge: Cambridge University Press.

García Velasco, D. (2007). Lexical Competence and Functional Discourse Grammar. Alfa, São Paulo, 51(2), 165-187.

Haack, S. (1992). "Extreme Scholastic Realism": Its relevance to philosophy of science today. Transactions of the Charles S. Peirce Society, 28(1), 19-50.

Hauser, M., Chomsky, N., \& Fitch, W. T. (2002). The language faculty: What is it, who has it, and how did it evolve? Science, 298, 1569-1579.

Hauser, M. D., \& Fitch, W. T. (2003). What are the uniquely human components of the language faculty? In M. H. Christiansen and S. Kirby (Eds.), Language evolution (pp. 158-181). Oxford: Oxford University Press.

Hawkins, J. A. (2004). Efficiency and complexity in grammars. Oxford: Oxford University Press.

Hengeveld, K., \& Mackenzie, J. L. (2008). Functional discourse grammar. Oxford: Oxford University Press.

Hengeveld, K. \& Mackenzie, J.L. (2010). Functional Discourse Grammar. In B. Heine and H. Narrog (Eds.), The Oxford handbook of linguistic analysis (pp. 367-400). Oxford: Oxford University Press.

Hengeveld, K. \& Mackenzie, J. Lachlan (2014). Grammar and Context in Functional Discourse Grammar. Pragmatics, 24(2), 203-227.

Hengeveld, K. \& Pérez Quintero, M.J. (2001). Descriptive adequacy in Functional Grammar. Revista Canaria de Estudios Ingleses, 42, 103-117.

Hopper, P. 1988. Emergent grammar and the A Priori Grammar Postulate. In D. Tannen (Ed.), Linguistics in context: Connecting observation and understanding (pp. 117134). Norwood N.J.: Ablex.

Hutchins, E. (1995). Cognition in the wild. Cambridge, Mass.: The MIT Press.

Hutchins, E. (2000). Distributed cognition. <http://www.artmap-research.com/wpcontent/uploads/2009/11/Hutchins_DistributedCognition.pdf> (August 18, 2014)

Hymes, D.H. (1972). On Communicative Competence. In J. B. Pride and J. Holmes (Eds.), Sociolinguistics. Selected readings (pp. 269-293). Harmondsworth: Penguin.

Jackendoff, R. (2002). Foundations of language. Oxford: Oxford University Press.

Jackendoff, R. (2011). What is the human language faculty? Two views. Language, 87(3), 586-624.

Jakobson, R. (1960). Closing statement: Linguistics and poetics. In T. Sebeok (Ed.), Style in language (pp. 350-377). New York: Wiley.

Jakobson, R. (1965). Quest for the essence of language. Diogenes, 13(51), 21-37.

Jakobson, R. (1971). Toward a nomothetic science of language. In Selected Writings vol. II: Word and language (pp. 369-602). The Hague: Mouton.

Jakobson, R. (1987). Language in Literature. (K. Pomorska and S. Rudy, Eds.). Cambridge, Mass./London, England: Harvard University Press.

Jakobson, R. (1990). On language. (L. R. Waugh and M. Monville-Burston, Eds.). Cambridge, Mass./London, England: Harvard University Press. 
Kendon, A. (2004). Gesture: Visible action as utterance. Cambridge: Cambridge University Press.

Kopp, S., Bergmann, K., \& Wachsmuth, I. (2008). Multimodal communication from multimodal thinking: Towards an integrated model of speech and gesture production. International Journal of Semantic Computing, 2(1), 115-136.

Kurcz, I. (2004). Communicative Competence and Theory of Mind. Psychology of Language and Communication, 8(2), 5-18

Langacker, R.W. (1987). Foundations of cognitive grammar, vol. I: Theoretical Prerequisites. Stanford, Ca.: Stanford University Press.

Langacker, R.W. (1991). Foundations of cognitive grammar, vol. II: Descriptive Application. Stanford, Ca.: Stanford University Press.

Langacker, R.W. (2001). Discourse in cognitive grammar. Cognitive Linguistics, 12(2), 143-188.

Levelt, W.J.M. (1989). Speech: From intention to articulation. Cambridge, Mass.: The MIT Press.

Luhmann, N. (1995). Social systems (J. Bednarz, Jr. and D. Baecker, Trans.). Stanford, Ca.: Stanford University Press.

Maturana Romesín, H., \& Varela García, F. J. (1980). Autopoiesis and Cognition. The realization of the living. Boston: D. Reidel Publishing Company.

Maturana Romesín, H., \& Verden-Zöller, G. (1996). Biology of love. In G. Opp and F. Peterander (Eds.), Focus Heilpädagogik-Projekt Zukunft. Festschrift zum 70. Geburtstag von Otto Speck. Munich: Ernst Reinhardt. (In P. Bunnell (Ed.). Imprint Academic, 2008.)

McLuhan, M. (1964). Understanding media: The extensions of man. New York: McGraw Hill.

McNeill, D. (1992). Hand and mind: What gestures reveal about thought. Chicago: University of Chicago Press.

McNeill, D. \& Duncan, S. D. (2000). Growth points in thinking-for-speaking. In D. McNeill (Ed.), Language and gesture: Window into thought and action (pp. 141 161). Cambridge: Cambridge University Press.

McNeill, D. (2005). Gesture and thought. Chicago: University of Chicago Press.

McNeill, D. (2006). Gesture and thought. Manuscript presented at "The Summer Institute on Verbal and Non-verbal Communication and the Biometrical Principle," Sept. 2-12, 2006, Vietri sul Mare, Italy. (Anna Esposito, Org.)

Mead, G.H. (1934). Mind, self, and society. (C. W. Morris, Ed.) Chicago: University of Chicago Press.

Melinger, A., \& Levelt, W. J. M. (2004). Gesture and the communicative intention of the speaker. Gesture, 4(2), 119-141.

Nedergaard Thomsen, O. (2006). Towards an integrated functional-pragmatic theory of language and language change. In commemoration of Eugenio Coseriu (1921-2002). In O. Nedergaard Thomsen (Ed.), Competing models of linguistic change. Evolution and beyond (pp. 307-337). Amsterdam: Benjamins.

Nedergaard Thomsen, O. (2008). Funktionel Diskurs Grammatik-og Funktionel Pragmatik. Nydanske Sprogstudier, 36, 63-119.

Nedergaard Thomsen, O. (2010). From talking heads to communicating bodies: Cybersemiotics and total communication. Entropy, 12, 390-419. 
Public Journal of Semiotics 6 (1)

Nedergaard Thomsen, O. (2014). Walking together we create the road-Linguistic conventions and conventionalisation in a Peircean perspective. (In print in D. Duncker and B. Perregaard (Eds.), Amsterdam: John Benjamins.)

Nelson, K. (1998). Language in cognitive development. Emergence of the mediated mind. New York: Cambridge University Press.

Peirce, C.S. (1923[1998]). Chance, love, and logic: Philosophical essays. (M. R. Cohen, Ed.). London: Kegan Paul, Trench, Trubner \& Company; New York: Harcourt, Brace \& Company. (In K. L. Ketner (Ed.). Lincoln NY/London England: University of Nebraska Press.

Peirce, C.S. (1902[1955]). Three trichotomies of signs. In J. Buchler (Ed.), Philosophical Writings of Peirce (pp. 101-104). New York NY: Dover, 1955.

Pinker, S., \& Bloom, P. (1990). Natural language and natural selection. Behavioral and Brain Sciences, 13, 707-784.

Rijkhoff, J. (1995). Bystander and Social Deixis: Some Programmatic Remarks on the Grammar Pragmatics Interface. Working Papers in Functional Grammar, WPFG, 58, $30 \mathrm{pp}$.

Richerson, P. J., \& Boyd, R. (2001). Culture is Part of Human Biology: Why the superorganic concept serves the human sciences badly. In M. Goodman and A. S. Moffat (Eds.), Probing human origins. Cambridge, Mass.: The American Academy of Arts \& Sciences. (In S. Maasen and M. Winterhager (Eds.), Science Studies: Probing the Dynamics of Scientific Knowledge. Bielefeld: transcript Verlag, 2001.)

Rizzolatti G., \& Sinigaglia C. (2010). The functional role of the parieto-frontal mirror circuit: interpretations and misinterpretations. Nat. Rev. Neurosci. 11, 264-274.

Searle, J.R. (1990). Collective intentions and actions. In P. Cohen, J. Morgan, and M. Pollack (Eds.), Intentions in communication (pp. 401-415). Cambridge, Mass.: The MIT Press.

Searle, J.R. (2010). Making the social world: The structure of human civilization. Oxford: Oxford University Press.

Slobin, D.I. (1987). Thinking for speaking. Proceedings of the Thirteenth Annual Meeting of the Berkeley Linguistics Society, BLS, 13 (1987): 435-445.

Strohner, H. (2001). Kommunikation: Kognitive Grundlagen und praktische Anwendungen. Wiesbaden: Westdeutscher Verlag.

Thibault, P.J. (2011). First-order languaging dynamics and second-order language: The distributed language view. Ecological Psychology, 23(3), 210-245.

Tomasello, M. (2003). Constructing a language: A usage-based theory of language acquisition. Cambridge, Mass.: Harvard University Press.

Tomasello, M., Carpenter, M., Call, J., Behne, T., \& Moll, H. (2005). Understanding and sharing intentions: The origins of cultural cognition. Behavioral and Brain Sciences, 28, 675-691.

von Uexküll, J. (1909). Umwelt und Innenwelt der Tiere. Berlin: Julius Springer.

Wittgenstein, L. (1953). Philosophische Untersuchungenk. Suhrkamp, Frankfurt 2001.

Zlatev, J. (2011). From cognitive to integral linguistics and back again. Intellectica, $56(2), 125-147$.

Author addresses 
Ole Nedergaard Thomsen

Department of Culture and Identity

Roskilde University, Denmark

ont@ruc.dk

\section{Søren Brier}

Department of International Business Communication

Copenhagen Business School, Frederiksberg, Denmark

sb.ibc@cbs.dk

\section{About the authors}

Ole Nedergaard Thomsen has Ph.D. in functional linguistics and is conducting research and administrative work at Roskilde University and in the private company AnkiroDigital Tools on Human Terms, Copenhagen. Søren Brier is Professor of Semiotics in the Information, Cognition and Communication Sciences at the Department of International Business Communication at Copenhagen Business School. He is the creator of the transdisciplinary framework Cybersemiotics, founder and editor-in-chief of the journal Cybernetics \& Human Knowing, co-founder of the International Association for Biosemiotic Studies and its journal. 